\title{
A Comprehensive Review of Erectile Dysfunction in Men with Diabetes
}

\author{
Author \\ Z. A. Kamenov \\ Affiliation \\ Clinic of Endocrinology, Alexandrovska University hospital, Medical University-Sofia, Sofia, Bulgaria
}

\author{
Key words \\ erectile dysfunction \\ diabetes \\ - diabetic neuropathy \\ - PDE-5 inhibitor \\ intracavernosal injection \\ penile implant
}

received 29.09.2014

first decision 29.09.2014

accepted $\quad 01.10 .2014$

\section{Bibliography}

DOI http://dx.doi.org/

10.1055/s-0034-1394383

Published online:

December 11, 2014

Exp Clin Endocrinol Diabetes

2015; 123: 141-158

(C) J. A. Barth Verlag in

Georg Thieme Verlag KG

Stuttgart · New York

ISSN 0947-7349

\section{Correspondence}

Prof. Z. A. Kamenov

Clinic of Endocrinology

Medical University - Sofia

1, G.Sofiiski Str.

Sofia 1431

Bulgaria

Tel.: + 35/988/7726 683

Fax: + 35/928/229 550

zkamenov@hotmail.com

\section{Abstract \\ $\nabla$}

Erectile dysfunction (ED) is more common in men with diabetes (DM). Dependent on the selected population, age, DM type and duration, the prevalence of diabetic ED (DED) varies from 32 to $90 \%$. In $12-30 \%$ of men ED is the first sign of diabetes, diagnosed later. Today men with diabetes live longer than ever, and develop more late diabetic complications. Having in mind also the global ageing of the world population all this data suggests an increasing number of men with DED in the future. The main factors playing in the complex pathogenesis of DED are diabetic neuropathy (oxidative stress, polyol pathway, advanced glycation end-products, nerve growth factor deficiency, dysfunction of protein kinase $\mathrm{C}$, tissue remodeling, etc.), macrovascular arterial disease (endothelial dysfunction, abnormal collagen deposition and smooth muscle degeneration, dyslipidemia, arterial hypertension, veno-occlusive dysfunction, etc.), hypogonadism, structural remodeling of the corporeal tissue, psychogenic components and adverse drug reactions. The diagnostic process is based on the results of questionnaires, neurological, vascular (Doppler) and other more rarely used investigations.

\section{Introduction}

\section{$\nabla$}

According to the $6^{\text {th }}$ edition of the International Diabetes Federation Diabetes atlas (2013) nowadays, there are 382 million people with diabetes mellitus (DM) in the world. The global prevalence is $8.3 \%$ of the adult population, and the disease causes at least 548 billion US\$ in health expenditure $=11 \%$ of total health spending on adults. The prognosis is alarming - in 2035 it is expected the number of people with diabetes to be 592 million with a global prevalence of $10.1 \%$ (IDF, 2013). Over the past 2 decades DM has
Because of the complex pathogenesis of DED diabetic men represent a "difficult" treatment group. The difficulties are from the "beginning", because patients do not talk about their problem spontaneously, and doctors do not ask about it. The treatment of DED should be team work, preferably including also specialists in sexual medicine. Psychological support and counseling of the couple is necessary in most cases. The general measures include implementation of a healthier lifestyle, improved glycemic-, lipids-, and arterial pressure control, and careful re-evaluation of the concomitant medications. The specific treatment includes as first line therapy the inhibitors of phosphodiesterase type 5 (PDE-5) with lesser effectiveness compared to non-DM men. There are rare studies with selected diabetic populations and even less with head-to-head comparisons between the PDE-5 inhibitors. Men with DM have a higher prevalence of hypogonadism. Testosterone replacement therapy should be started in symptomatic men with proven hypogonadism and no contraindications. Vacuum constriction devices and intracavernous or intraurethral applications of vasoactive drugs are the second line therapy. Vascular surgery rarely comes into consideration. The penile implant is the last and effective option in men with severe DED.

become an epidemic, mostly because of type 2 (DM2), which represents $90-95 \%$ of the cases with DM, although the incidence of type 1 (DM1) has also doubled (Ryan, 2009). The physical, emotional, financial and social burden of DM is caused mostly by late complications of diabetes (๑ Fig. 1).

The progress in understanding the pathogenesis of DM, the increased perception and sensitivity of society, and the broad spectrum of therapeutic tools in the last years has led to the practical elimination of ketoacidosis and other acute diabetic complications as a cause of death in 
developed countries, and to the improvement of glucemic control to the highest level so far. These favourable factors made it possible today for people with DM to live longer than ever, which increases the chance of developing late complications of the disease. Thus, demographic tendencies and epidemiological prognoses highlight an increasing importance of chronic diabetic complications in the future including diabetic erectile dysfunction.

Erectile dysfunction (ED) is the persistent or recurrent inability to attain or maintain an erection sufficient to complete sexual intercourse or another chosen sexual activity. During the last 15 years the scientific interest towards ED grew significantly because of:

1. Aging of the population and in particular the increasing life expectancy of men. The prevalence of ED increases with age. According to a WHO report (2008) it is expected that $35 \%$ of the population will be over 60 years in industrial countries in the year 2025 (NIC, 2008).
2. ED is common in men of all nations. As discussed below, the global aspects of the problem "Erectile dysfunction" were demonstrated in several large epidemiological studies.

3. There is increasing evidence of a direct link between ED and cardio-vascular diseases. ED is a marker of the vascular and in particular endothelial health of a man and it can be considered not only as a part of the quality of life but also as a predictor of its quantity (length) as well.

4. The release of the first PDE-5-inhibitor (sildenafil) on the market about 15 years ago, followed by vardenafil, tadalafil, avanafil and others, revolutionized the treatment of ED making it more effective, accessible, safe and cheap.

The prevalence of DM is increasing dramatically and it has been recognized as a pandemic disease. After the introduction of sildenafil in 1998 the number of publications about diabetic erectile dysfunction (DED) rose consistently ( $\bullet$ Fig. 2 ). Although ED is present in many non-diabetic men, DED may be considered as a late diabetic complication because to the above mentioned reasons some diabetes-specific aspects should be added:

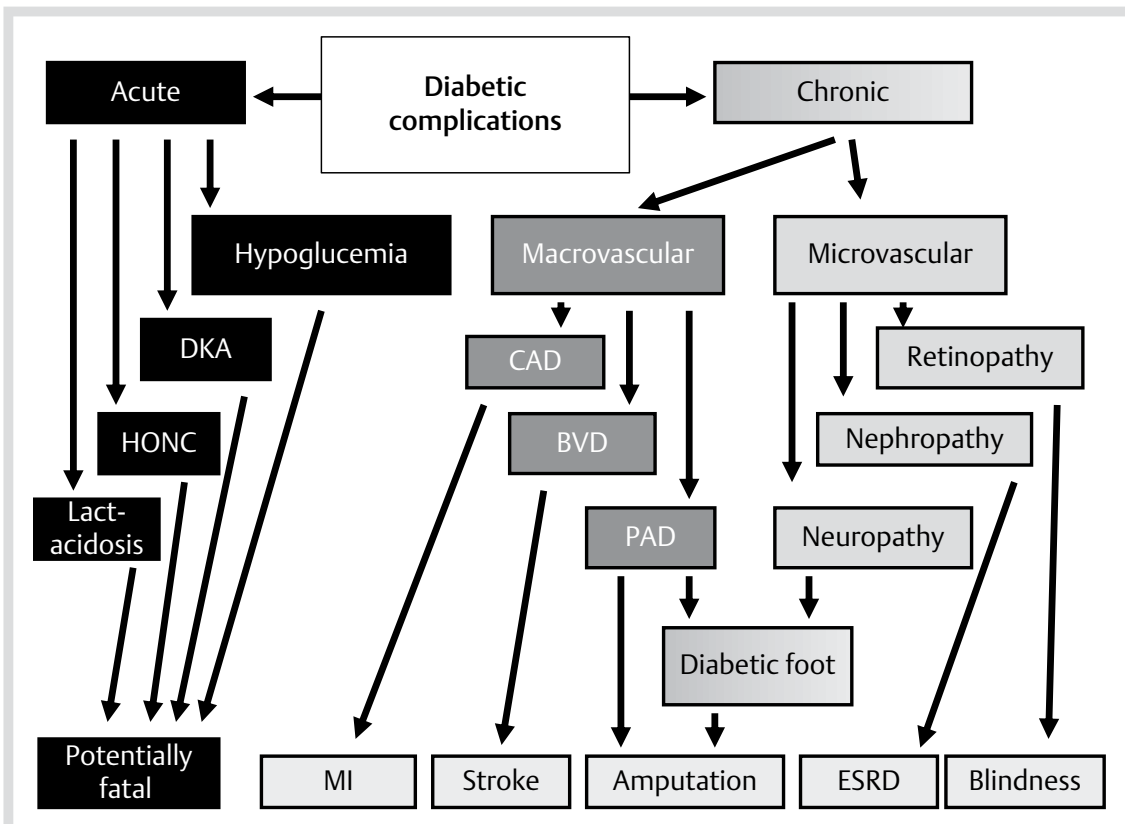

Fig. 1 Diabetic complications. DKA - diabetic ketoacidosis; HONK - hyperosmolar nonketotic coma; CAD - coronary artery disease; BVD - brain vascular disease; PAD - peripheral artery disease; $\mathrm{MI}$ - myocardial infarction; ESRD - end-stage renal disease.

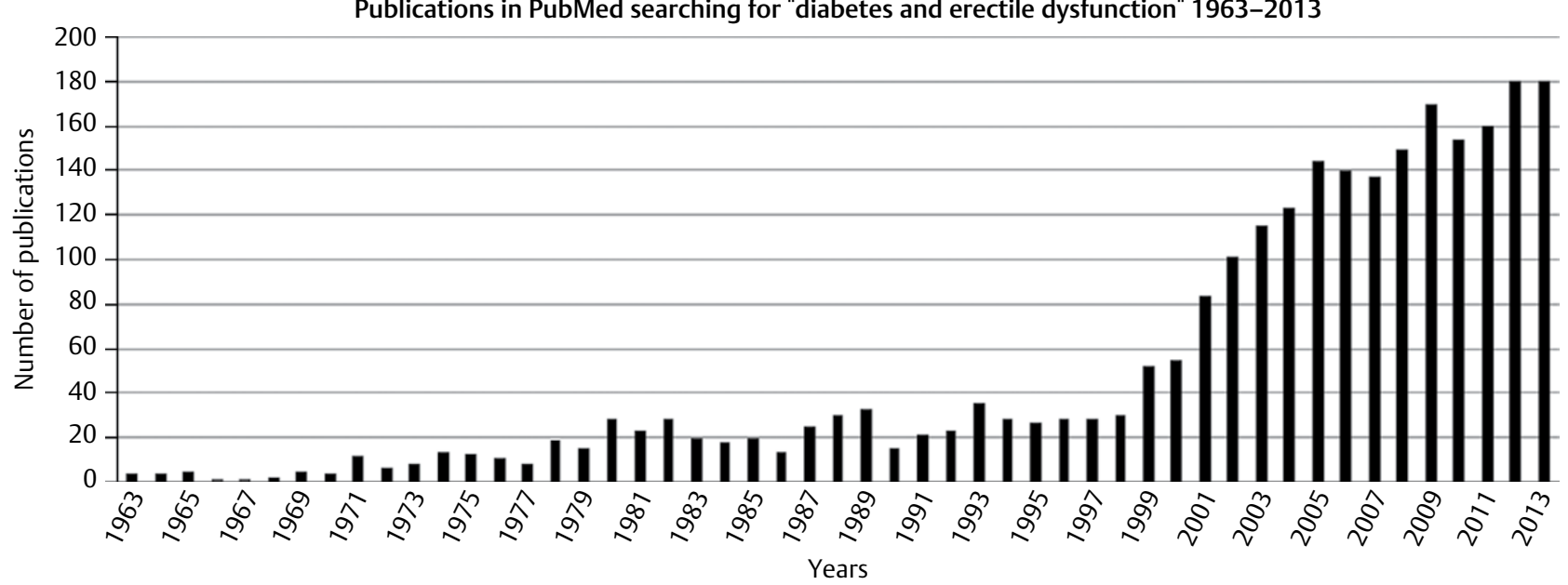

Fig. 2 Scientific publications during the last 50 years found in PubMed searching for "diabetes and erectile dysfunction". 
5. The prevalence of ED in men with DM is higher compared to healthy men.

6. Pathogenesis of DED is specific and more complex compared to non-diabetic one.

7. ED is more severe and impacts more profoundly the quality of life of diabetic men.

8. The effectiveness of the treatment for DED is lower compared to men without DM.

\section{Prevalence of DED}

$\nabla$

Depending on the age, duration and type of DM and the used diagnostic criteria epidemiological data about DED vary significantly between different studies. The evolution of DM2 commonly includes several pre-diagnostic stages, each including several years: insulin resistance and metabolic syndrome, prediabetes (impaired fasting glucose and/or impaired glucose tolerance), and undiagnosed diabetes. Many patients already have $\mathrm{ED}$ at the diagnosis of the disease. By analogy with the prediction of coronary artery disease, ED has been proven to be the first sign of diabetes, diagnosed later in $12-30 \%$ of men (Lewis, 2001; Adegite et al., 2009). A recent study found in a sample of 499 men (mean age $58.8 \pm 8.8$ years) with new or recently diagnosed DM2: mild DED in $19.4 \%$, mild-to-moderate in $15.4 \%$, moderate in $10.4 \%$, and severe in $21.6 \%$ of patients (Corona et al., 2014). ED is 3-4 times more common in diabetics compared to the general population (Martin-Morales et al., 2001; Feldman et al., 1994). During the first 10 years after the diagnosis of DM, DED is established in more than half of the men (Vinik, Richardson, 1998). We found a prevalence of DED of $44.7 \%$ among diabetic men aged $53.0 \pm 12.5$ years with diabetes $(74 \%$ DM2) duration of $8.6 \pm 6.7$ years and mean BMI $29.0 \pm 4.3 \mathrm{~kg} / \mathrm{m}^{2}$ (Kamenov et al., 2007). Reviewing the literature Malavige, Levy (2009) estimated a range of $35-90 \%$ reported in different studies from different countries (Malavige, Levy, 2009). The prevalence of ED in type 1 diabetes (DM1) is $32 \%$ and in type 2 (DM2) it is $46 \%$ (Vickers, Wright, 2004). According to 2 studies from different countries the prevalence of DED increases from $9 \%$ in the age interval $20-29$ years and $15 \%$ between $30-34$ to $95 \%$ in 60-70-year-old men and this increase correlates with the duration of diabetes, poor metabolic control and diabetic complications (Fedele et al., 1998; Smith, 1981). Multivariate analyses of several population based cohorts show that of all risk factors diabetes impacts the highest risk for ED with an age adjusted relative risk of 1.3-3 depending on diabetes type (Chitaley et al., 2009a; Chitaley, 2009b.; Bacon et al., 2002; Johannes et al., 2000).

\section{Pathogenesis of DED}

$\nabla$

Detailed description of the physiology of erectile function (EF) is not an object of this paper. In short, the erection is a complex process in which psychological, social, endocrine, paracrine, neural, vascular and other factors take part. The penis is a hydraulic organ whose state - from relaxation to different phases of erection is determined by the grade of fullness with blood of corpora cavernosa. Their volume is defined by 2 variables - arterial inflow and venous outflow. The capacity of the filling terminal helical arteries is determined by NO-dependent smooth muscle relaxation. Different stimuli - psychogenic (vis- ual, auditory, olfactory, memory, fantasy) or reflectory (tactile) activate the central and/or peripheral neuronal chains leading to synthesis and secretion of NO from the non-adrenergic-noncholinergic (NANC) neuronal terminals in the cavernosal bodies through activation of neuronal nitric oxide synthase (nNOS). This small amount of NO triggers initial smooth muscle relaxation starting the hemodynamic process of erection. Further, receptor mechanisms and the shear stress in the vascular wall activate phosphatidylinositol-3-kinase/protein kinase B (Akt) pathway leading to activation of endothelial nitric oxide synthase (eNOS) and further NO release from the penile endothelial cells. Binding of the released neural and endothelial NO to soluble guanylate cyclase in the smooth muscle cells (SMC) increases cyclic guanosinemonophosphate (cGMP) levels and cGMPdependent protein kinase $\mathrm{G}$ (PKG) activity. As a consequence cell membrane Ca-channels are closed decreasing the $\mathrm{Ca}++$ influx in the cell and from the other side cytosolic $\mathrm{Ca}++$ is retained in the endoplasmic reticulum. The opening of the Ca-dependent potassium channels on the membrane leads to potassium outflux and hyperpolarization. Finally, the cytosolic $\mathrm{Ca}++$ depletion causes cavernosal SMC relaxation leading to increased blood inflow through the helical arteries, sinusoidal filling and cavernosal dilation. The volume of corpora cavernosa increases and a compression of the draining venous vessels (emissary veins) in subtunical venular plexus against the rigid tunica albuginea occurs with a consequence - venous occlusion, decrease of outflow and further increase of intracavernosal pressure. The process of erection needs an intact cavernosal structure, characterized by abundant elastic fibers and less collagen.

The detumescence initiates with activation of the sympathetic neurons and liberation of norepinephrine from the adrenergic terminals of the cavernosal nerve, as well as endothelins and $\mathrm{PgF}_{2 \alpha}$ from the endothelial cells covering the cavernosal sinusoids. An increase in intracellular calcium activates myosin light chain (MLC) kinase and phosphorylation of MLC to generate SMC contraction. Additional pathways such as RhoA/Rho-kinase lead to the sensitization of the SMC contractile apparatus to calcium, promoting contraction. Activation of Rho-kinase results in inhibition of MLC phosphatase and continued expression of phosphorylated MLC. The RhoA/Rho-kinase pathway is a predominant calcium-sensitizing pathway to mediate continuous smooth muscle tone in the penis. Protein kinase $\mathrm{C}$ (PKC) is also calcium sensitizing and acts to inhibit MLC phosphatase, also promoting the contractile response (Hidalgo-Tamola, Chitaley, 2009).

Disturbances of each of the described consecutive stages from the erotic stimuli to the venous drainage may compromise the process causing ED. The pathogenetic concept about ED evolved from the mostly psychogenic in the past to the leading organic currently. It should be mentioned that psychogenic and organic disturbances interplay in every case of ED and cannot be separated absolutely even for didactic reasons. The similarities of dilatation mechanisms in corpora cavernosa and the remaining arterial vessels in the body, based on the key role of NO, explain the common mechanism of their deterioration in endothelial dysfunction. The presence of cardio-vascular disease increases significantly the likelihood for ED (Martin-Morales et al., 2001). From the other side, ED may be the first sign of existing but still undiagnosed CVD (Montorsi et al., 2003).

The pathogenesis of DED is much more complex compared to non-diabetic men ( $\Theta$ Fig. 3 ). During the last years special atten- 


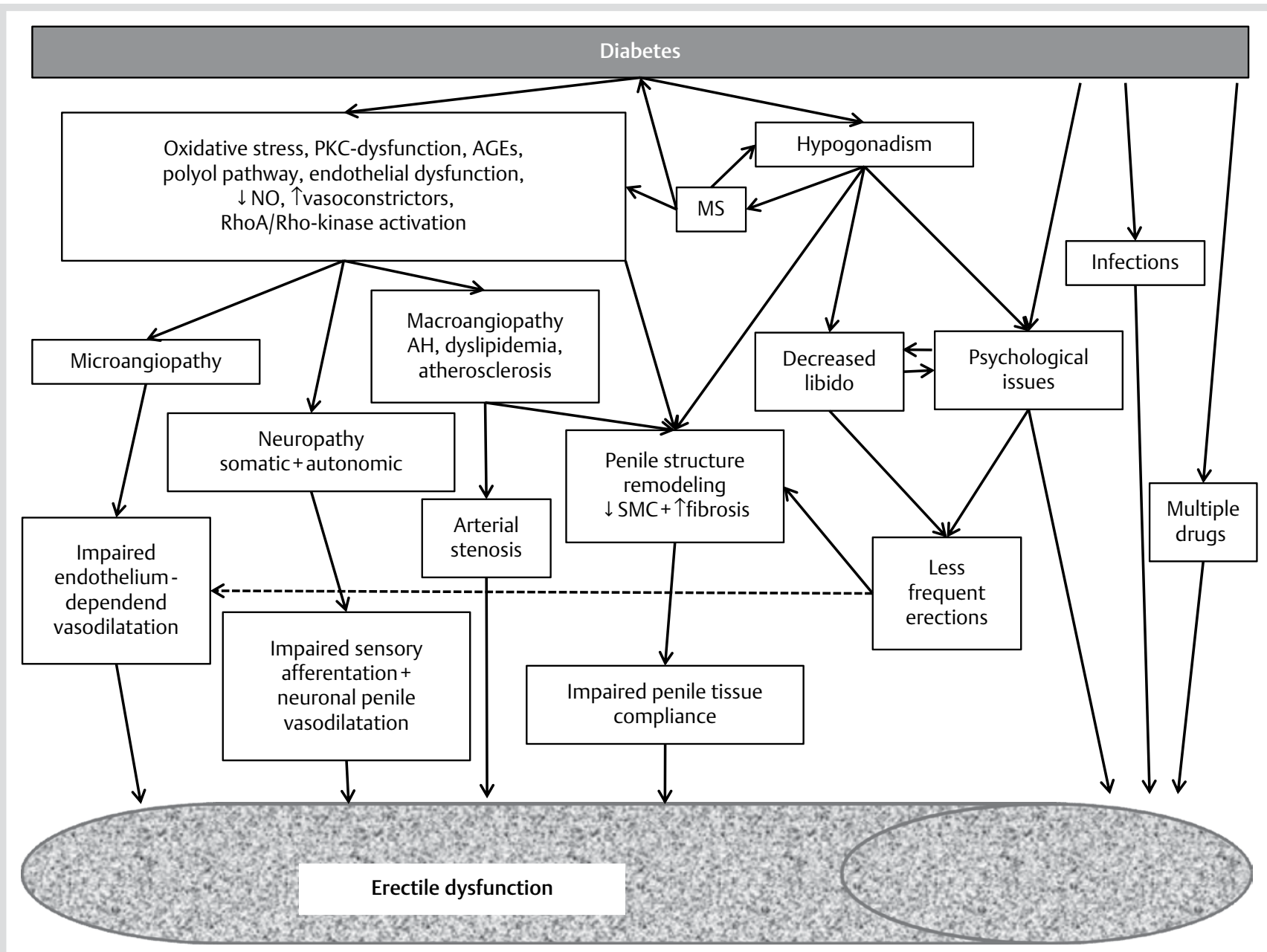

Fig. 3 Pathogenesis of DED. AGEs - advanced glucation end products; PKC - protein kinase C; NO - nitric oxide; MS - metabolic syndrome; SMS - smooth muscle cells; $\mathrm{AH}$ - arterial hypertension.

tion has been paid to the importance of DM as a vascular risk factor. It accelerates the development of endothelial dysfunction - an earlier event of vascular disease, induces oxidative stress and dyslipidemia, potentiates atherosclerotic process, aggravates arterial hypertension, etc. A vicious pathogenetic circle between DM and hypogonadism perpetuates - men with DM have lower levels of testosterone and men with hypogonadism have an increased risk of development of obesity, metabolic syndrome and DM with the full spectrum of their unfavorable cardiovascular consequences (Mulligan et al., 2006). This global vascular disorder takes place in the cavernosal bodies as well, where other more DM-specific pathogenetic biochemical mechanisms develop:

\section{Endothelial dysfunction}

This is probably the most discussed aspect of DED in the literature. Investigating the function of NO/cGMP signalling in human erectile tissues J. Angulo et al. (2010) used human corpus cavernosum (HCC) strips and penile resistance arteries (HPRA) collected from penile specimens from organ donors (OD) and from diabetic and non-diabetic men with ED undergoing penile prosthesis implantation (Angulo et al. (2010)). The relaxations to acetylcholine, electrical field stimulation, sodium nitroprusside, and sildenafil were evaluated in phenylephrine-contracted HCC and norepinephrine-contracted HPRA and cGMP content in HCC was also determined. The impairment of endothelium-dependent relaxation in HCC and HPRA from ED patients was exacerbated by diabetes - E(max) 76.1, 62.9, and $49.3 \%$ in HCC and 73.1, 59.8, and 46.0\% in HPRA from OD, non-diabetic and diabetic ED, respectively. Hypertension, hypercholesterolemia, or aging did not exert a further impairment of endothelial relaxation among ED patients. DM also caused a further impairment of neurogenic relaxation in HCC and HPRA. The basal and stimulated content of cGMP in HCC was significantly decreased in patients with ED, but specially reduced in diabetic patients. Diabetes clearly impaired PDE5 inhibitor-induced vasodilation of HPRA from ED patients. The authors concluded that ED is related to impaired vasodilation, reduced relaxant capacity, and diminished cGMP content in penile tissue. These alterations are more severe in diabetes and accompany reduced relaxant efficacy of PDE5 inhibition. Thus, an exacerbated reduction of NO/cGMP signaling could be responsible for ED in diabetic men and would explain their reduced response to treatment.

- NO bioavailability may be decreased by suppressed eNOS expression and/or activity or by increased NO scavenging. Jesmin et al. (2004) reported reduction of eNOS mRNA expression suggesting an eNOS deficient expression at transcriptional level in OLETF diabetic rats (Jesmin et al., 2003). In the same study decreased vascular endothelial growth factor (VEGF) expression and mRNA transcription in penile tissues 
was also found. It should be mentioned that the Akt-dependent pathway mediates both shear stress and VEGF phosphorylation of eNOS (Musicki et al., 2004). The effects of VEGF include endothelial cell proliferation, migration, angiogenesis, and anti-apoptosis, increased eNOS phosphorylation and expression of anti-apoptotic proteins. There is strong evidence that VEGF is a survival factor for endothelial cells (Dimmeler, Zeiher, 2000). At the molecular level, VEGF can upregulate eNOS expression in endothelial cells (Papapetropoulos et al., 1997). Furthermore, increased expression of eNOS has been reported in the rat penis after intracavernosal injection with VEGF (Lin et al., 2002). These findings support the importance of VEGF as an eNOS inducer. It would be logical to assume that the reduced expression of eNOS shown by Jesmin et al. (2004) in the OLETF rat penis may be causally related to the decrease in VEGF expression in the tissue. Unlike eNOS, nNOS does not appear to be inducible by VEGF (Sheehy et al., 1997). The penile expression level of nNOS has been documented to remain unchanged in VEGF-treated rats (Lin et al., 2002). Thus, the VEGF-triggered biochemical events probably have no targets in the nNOS gene, which continues to produce nNOS transcripts at a steady level.

- Oxidative stress is a key pathogenic factor in the development of diabetic complications. Chronic hyperglycemia induces free radical (reactive oxygen species - ROS) production through formation of advanced glycation end-products (AGE), lipid peroxidation, polyol pathway activation, superoxide production, and the activation of protein kinase C. ROS participate in most studied mechanisms for the initiation and maintenance of functional and structural deterioration. Increased oxidative activity and the expression of inflammatory markers are seen in patients with DED. Circulating monocyte activity and expressions of inflammatory markers such as endothelin-1 (ET-1) and intracellular adhesion molecule-1 (ICAM-1) are used as markers for ROS and inflammation (Hidalgo-Tamola, Chitaley, 2009).

- Advanced Glycation End-products (AGEs). Normally with aging every tissue in the body is glycated in some extent. In hyperglycemic conditions the glycation process is more active and leads to micro-structural changes on a molecular level, which can further compromise the function of the tissue and finally lead to macro-structural deterioration. AGEs bond covalently to the vascular collagen leading to thickening of the vascular wall, deceased elasticity, endothelial dysfunction and atherosclerosis (Bucala et al., 1991; Singh et al., 2001a). Interaction between AGEs and endothelial cells up-regulates adhesion molecules that mediate vascular damage. AGE also stimulates cytokine expression on monocytes and macrophages (Yan et al., 2008). AGEs are increased in corpora cavernosa of rats and men with DM and cause impaired cavernosal smooth muscle relaxation and ED in diabetic rats (Seftel et al., 1997; Cartledge et al., 2001b; Usta et al., 2003). One important mechanism for decreasing of cavernosal compliance and smooth muscle relaxation is through the generation of free radicals which react with NO and decrease its availability. Increased penile levels of ROS were found in diabetic rats. The resultant most reactive peroxinitrite is involved in cell damage and death. Summarizing, AGEs contribute to the development of DED by generating free radicals leading to oxidative cell damage and by quenching NO (Cartledge et al., 2001b; Bivalacqua et al., 2005; Khan et al., 2001).
- Endothelins. Endothelin has 3 isopeptides (1,2 and 3) and 2 receptors bound to G-protein (ETA and ETB). ET-1 is a powerful vasoconstrictor released from the vascular endothelium in the penis Moore, Wang (2006). There is evidence that DED is related to a disturbed balance towards increased vasoconstriction, caused by endothelin and its receptors (Bivalacqua et al., 2003; Christ et al., 1995). The plasma levels of ET-1 are increased in diabetic men (Clozel et al., 1992). ETA-receptors are located on the SMC and induce vasoconstriction and cell proliferation. ETB-receptors are presented mostly on the vascular endothelium and induce vasodilatation through NO and prostacyclin release (Bivalacqua et al., 2003; Sima et al., 1996). On the contrary, these receptors mediate vasoconstriction in some arteries like coronary in dogs and mammary in men (Clozel et al., 1992; Teerlink et al., 1994). It was found that ETB-receptors are up-regulated in the cavernosal bodies of diabetic rabbits where it is supposed to have constrictive role. In this way an increase in ETB receptors and their ligands may cause disbalance and vasoconstriction (Sima et al., 1996). It is considered that the mitogenic effect of ETB causes early ultrastructural atherosclerotic changes in diabetics (Lu et al., 2004).

- RhoA-Rho kinase. RhoA is a GTB-binding protein affected by Rho-kinase. The ET1 induced vasoconstriction is related to the RhoA-Rho kinase pathway (Park et al., 2002; Wang et al., 2002; Buyukafsar, Un, 2003) the activation of which suppresses eNOS (Ming et al., 2002). Rho-kinase is found in the cavernosal tissue of rats, rabbits and men and is activated in diabetic rats. It is considered that the RhoA-Rho kinase pathway potentiates ED by the decreased production of NO in the penis (Rees et al., 2002; Bivalacqua et al., 2004; Chua et al., 2006).

Several other mechanisms have been described in which hyperglycemia leads to functional and structural changes in cavernosal bodies and arteries. The described complex pathogenetic attack decreases the capacity of SMC relaxation and functional dilatation of cavernosal structures, but also limits the penile arterial inflow through atherosclerotic changes.

\section{Diabetic neuropathy (DN)}

DN is the most common diabetic complication, affecting 10-90\% of people with diabetes, depending of the diagnostic criteria and the age and duration of DM (Vinik et al., 1992; Young et al., 1993; Dyck et al., 1993; Tesfaye et al., 1996). Some studies showed an earlier development of DN in men, compared to women (Aaberg et al., 2008; Kamenov et al., 2010). Neuropathy is a very important pathogenetic factor in the development of DED. Because DN affects all levels of the neural system, disturbances could also happen on all levels in the complex process of erection - from the central initiation to the penis. In the literature much more attention is paid to the vascular aspects of DED compared to the neural ones (Kamenov, Traykov, 2012).

The central aspects of erection have been investigated in some studies, from fundamental investigations of sexual behavior to functional MRI imaging and PET in the phase of REM sleep, associated with nocturnal penile tumescences, as well as the whole sexual cycle in men (Nofzinger, 1997). It should be mentioned that central aspects of DN and DED have been much less investigated probably because of the insufficient options for diagnostic methods and selective therapeutic influence. Recently, MRI for structural (Frøkjær et al., 2013) and functional MRI for structural and functional changes and other methods have been used 
for investigating the central aspects of DN (Selvarajah et al., 2014; Wilkinson et al., 2013).

In the clinical classification of DN traditionally DED is positioned in the genito-urinary autonomic DN. The initial stage of the erection process at penile level - NANC nerve endings nNOS activation and NO release has been shown to be impaired in animal models of DM1 and (although less convincingly) in DM2 (Hidalgo-Tamola, Chitaley, 2009). Otsuka Long-Evans Tokushima fatty (OLETF) rats represent an appropriate model for spontaneously developed DM2 with its late complications (Kawano et al., 1992), including DN (Kamenov et al., 2006). OLETF rats showed decreased immunofluorescent staining for nNOS in dorsal nerves and $40 \%$ decrease in nNOS $160 \mathrm{kDa}$ protein expression relative to that of non-diabetic controls $(P<0.01)$, thus supporting an impaired nNOS effectiveness in DM2 (Jesmin et al., 2003). By applying different neurological tests it has been shown that diabetics with ED present more commonly with abnormal NCV, sphincter electromyography and vibration sensitivity compared to those without ED (Hakim, Goldstein, 1996; Hecht et al., 2001). The combination of sensory and autonomic disturbances leads to decreased sensory afferentation necessary for the initiation and maintenance of the erection, but also limits the effect of the critically necessary for the erection NO from the intracavernosal nerve terminals. In most studies no separate evaluation of the macro- and microvascular (including DN) complications is presented. We found that microangiopathy and in particular DN is a more important risk factor for DED than macroangiopathy (Kamenov et al., 2007). The presence of ED increased the likelihood to have macrovascular but in higher degree microvascular diabetic complications. These data support the crucial negative role of DN in the complex pathogenesis of DED and may explain why men with diabetes are more prone to ED compared to men with same degree of macrovascular disease but without DN.

\section{Hypogonadism}

is frequently associated with DM2 (Yagihashi et al., 2007; Bartolini et al., 2004; Corrales et al., 2004; Corona et al., 2007). There are strong causal links between the metabolic syndrome, ED and late onset hypogonadism. Even shortly after the diagnosis of DM2 the prevalence of hypogonadism (symptoms + TT $<3.2 \mathrm{ng} /$ $\mathrm{ml}$ ) is $17.6 \%$, but only $0.2 \%$ of the subjects in this study reported occasional use of testosterone and none a current therapy of frequent use (Corona et al., 2014). Later-on in the evolution of the disease, in the average diabetic population, choosing a cut-off of total testosterone (TT) $<10.4 \mathrm{nmol} / \mathrm{l}$ for evaluation of 2165 men aged $\geq 45$ years, visiting primary care practices in the United States, the investigators of HIM study reported that half of diabetic men were hypogonadal $=50.0 \%$ (45.5-54.4), $\mathrm{OR}(95 \% \mathrm{CI})=2.09$ (1.70-2.58) (Mulligan et al., 2006). Hypogonadism was also very common in other co-morbidities included in the metabolic syndrome: obesity $=52.4 \%(47.9-56.9) ; \mathrm{OR}=2.38$ (1.93-2.93), arterial hypertension $=42.4 \% \quad(39.6-45.2) ; 1.84$ (1.53-2.22), hyperlipidemia $=40.4 \%$ (37.6-43.3); 1.47 (1.231.76) respectively. Many studies support the weight-increasing effect of hypogonadism and the testosterone lowering effect of obesity. It is difficult to answer which one is the initial event hypogonadism or the metabolic syndrome. Even if the causeconsequence dilemma is still not definitely solved, the treatment should be directed to both problems.

Against the older opinion that testosterone is mostly a trigger of desire with limited importance for the lower levels of erection, a growing body of evidence supports its active participation and importance on all levels of the above described hierarchic structure of the erectile process ( $\bullet$ Fig. 4).

On the cerebral level testosterone acts by itself, but also as its metabolites after appropriate enzymatic transformations to estradiol (via aromatase) and to dihydrotestosterone (via 5-alpha reductase). It stimulates the synthesis, storage and release of pro-erectogenic neurotransmitters and modulates the neuronal activity, receptor sensitivity, neurotransmitter liberation, the socio-sexual behavior (increasing libido) and positively influencing dopamine, NO, oxytocine, etc. On the spinal level testosterone activates the androgen-sensitive motoneurons of $\mathrm{mm}$. bulbo- and ischiocavernosi and the androgen receptors in parasympathetic erectile area $\mathrm{S}_{2-4}$.

It is generally accepted that androgens are critical for the development, growth, and maintenance of penile erectile tissue. Animal studies showed testosterone dependency of the eNOS-containing cavernosae parasympathetic fibers (Baba et al., 2000). In animal models, androgen deprivation produces penile tissue atrophy concomitant with alterations in dorsal nerve structure, endothelial morphology, reduction in trabecular smooth muscle content, and an increased deposition of extracellular matrix. Further, androgen deprivation results in the accumulation of adipocytes in the subtunical region of the corpus cavernosum (Traish, Kim, 2005). Testosterone deprivation is followed by the programmed cell death of cavernosal SMC (Porst, 2007). Interestingly, testosterone stimulates both the initiator of the erection (NOS) and its terminator (PDE-5), thus fine balancing the whole process. Androgen deficiency diminishes protein expression and the enzymatic activity of nitric oxide synthases (eNOS and nNOS) and PDE-5. The androgen-dependent loss of erectile response is restored by androgen administration but not by administration of PDE- 5 inhibitors alone. These data suggest that androgens regulate trabecular smooth muscle growth and connective tissue protein synthesis in the corpus cavernosum. Further, androgens may stimulate the differentiation of progenitor cells into SMC and inhibit their differentiation into adipocytes. Clinical and preclinical studies have suggested that venoocclusion is modulated by the tone of the vascular smooth muscle of the resistance arteries and the cavernosal tissue and a balance between trabecular smooth muscle content and connective tissue matrix. In men with $E D$, venous leakage is thought to be a common condition among non-responders to medical management and is attributed to penile smooth muscle atrophy. Summarizing, Traish and Kim (2005) concluded that androgens

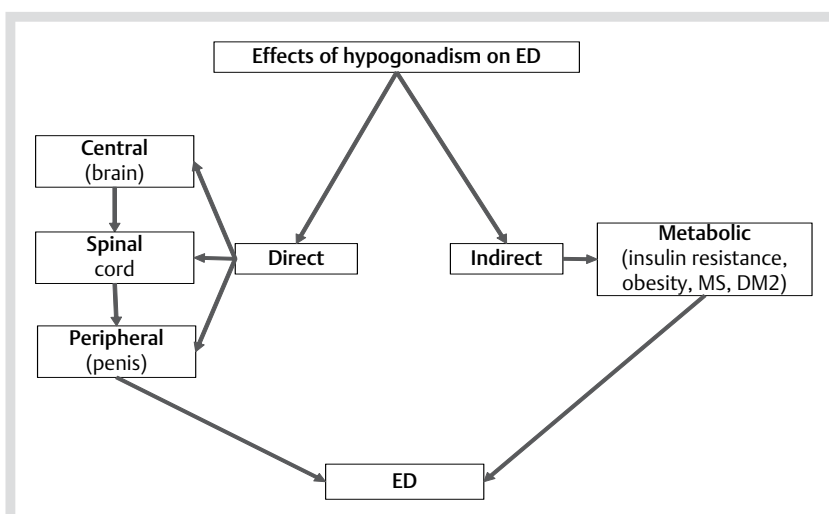

Fig. 4 Effects of hypogonadism on ED. MS - metabolic syndrome; DM2 - diabetes type 2; ED - erectile dysfunction. (modified from Kamenov, Frederique Courtois 2013). 


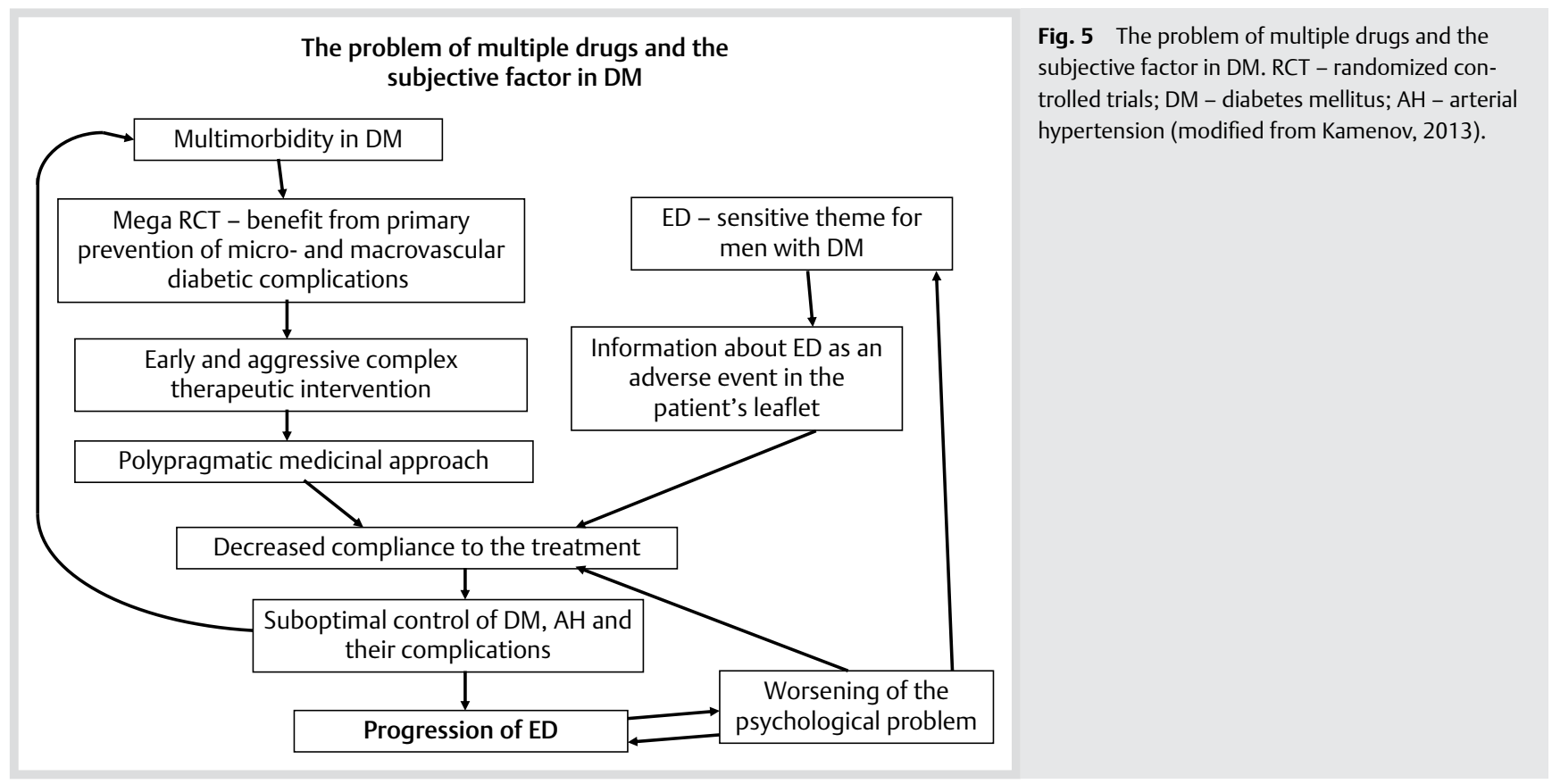

exert a direct effect on penile tissue to maintain EF and that androgen-deficiency produces a metabolic and structural imbalance in the corpus cavernosum, resulting in venous leakage and erectile dysfunction (Traish and Kim (2005)). The testosterone level necessary for normal EF still needs exact determination. Interventional studies in men have demonstrated the favorable effect of testosterone replacement therapy (TRT) on EF in men with organic hypogonadism, mostly in cases when it is the only reason for ED (Shabsigh, 2006). Other structural changes related to DM include the loss of normal cavernosal endothelium and SMC (Burchardt et al., 2000) and an increased deposition of collagen and thickening of the basal lamina leading to fibrosis (Jevtich et al., 1990).

\section{Other Sexual Dysfunctions}

DM is associated not only with ED but with all aspects of sexual dysfunction - sexual drive, ejaculatory function, sexual problems, sexual satisfaction, etc. (Burke et al., 2007). In patients with DM there is a strong association between ED and reduced libido ( $\mathrm{OR}=4.38,95 \% \mathrm{CI}=1.39-13.82)$ and an even stronger one between ED and premature ejaculation $(\mathrm{PE})=4.41(2.08-9.39)$ respectively. The presence of one of these 3 conditions (ED, PE and reduced libido) requires screening for the other 2 (Malavige et al., 2008). Corona et al. (2014) found PE, delayed ejaculation, and hypoactive sexual desire in $28.3,32.9$, and $58.4 \%$, respectively in men around the diagnosis of DM2 (Corona et al. 2014). A study from Minnesota demonstrated DM to be associated with decreased sexual desire, ejaculatory function and sexual satisfaction (Burke et al., 2006). Another study reported $80 \%$ of the interviewees to have sexual problems - decreased libido (50.3\%), PE (19.7\%), retrograde ejaculation (19.2\%). According to the answer to the question for having problems with the erection it appeared 51.5\% had ED and, according to IIEF, 87.9\% (Adegite et al., 2009). The sexual problem preceded the diagnosis of diabetes in $30.2 \%$. In $45.3 \%$ of cases no medical consultation has been sought.
Balanitis is more common in diabetes (16\%) compared to general population (5.8\%) (Fakjian et al., 1990). It has been shown that $12 \%$ of men have had balanitis during the last 2 years before the diagnosis of DM (Drivsholm et al., 2005). Inflammation, pain and discharge, related to mycotic balanitis may have somatic and psychological unfavorable effects on the erection and sexual intercourse. Phymosis, a condition where the foreskin cannot be fully retracted over the glans penis, is common in diabetes $-32 \%$ of men admitted to a urological clinic with phymosis have had DM (Drivsholm et al., 2005). Phymosis may cause pain and difficulties in physical and psychological aspects during coitus. Peyronie disease (induratio penis plastica) represents a usualy painful connective tissue disorder with abnormal curvature of the penis when erect due to chronic inflammation of the tunica albuginea, forming cord-like fibrous plaques from hardened scar tissue. Although a variety of treatments has been used none have been especially effective. It is associated with DM (El-Sakka, Tayeb, 2005) and correlates with its duration (Arafa et al., 2007). The prevalence in diabetic men varies from 8.1 to $18.3 \%$ (ElSakka, Tayeb 2005; Schwarzer et al., 2001; Tefekli et al., 2006). In patients with DED prevalence of $20.3 \%$ (Arafa et al., 2007) has been reported and 16 (Kadioglu et al., 2004) compared to $3.2 \%$ (Schwarzer et al., 2001) and 3.64\% (Rhoden et al., 2001) in nonselected populations.

DM is a disease, usually accompanied by several co-morbidities. The last clinical mega-trials recommended an early and aggressive therapeutic intervention aiming at primary prevention of micro- and macrovascular diabetic complications. The polypragmatic medication approach is typical in patients with DM ( $\odot$ Fig. 5). Many of the used drugs (antihypertensive, SSRI, neuropathic pain control, etc.) are claimed to have an unfavorable effect on EF. Men with DM are psychologically more sensitive and focused on the subject of ED. In many cases the information about possible ED as an adverse event of the particular medication read in the patient information leaflet, may compromise the understanding of the necessity for keeping normal blood sugar, lipids and blood pressure levels, interfering in this way with compliance and adherence to the treatment. This imposes a careful selection of the treatment options choosing a harmo- 
nized therapeutic scheme aiming at no between-drug interference but also no unfavorable effects on different aspects of the metabolic syndrome and ED in patients with DM.

\section{Diagnostic Process}

The diagnostic process in DED does not differ significantly from the usually described diagnostic algorithms for ED. The clinical workout for ED could be divided in 2 steps: (1) diagnosis - confirmation of the presence of ED and (2) differential diagnosis identification of all possible factors and causes for the development of the particular ED. The second step is very important for the treatment decision for all treatable pathogenetic factors ( $\bullet$ Table 1 ).

1. The diagnosis of ED is not a difficult one, but may be impeded by several mainly subjective obstacles. Men are usually distressed by the disease and ED and are ashamed to speak voluntarily about the problem ( $\bullet$ Fig. 6). Medical specialists with a general medical profile do not initiate this conversation as well because of lack of knowledge, interest, motivation or time. Consultation in this sensitive area needs special skills and practice in the field of sexual medicine - an interdisciplinary specialty with a growing number of experts. Several validated questionnaires may be used for the diagnosis of ED. The International Index of Erectile Function (IIEF) (Rosen et al., 1997 ) is currently the most widely used questionnaire (Basu,

Table 1 Main symptoms and signs of Late onset hypogonadism ( $\mathrm{LOH})$ in men.

$\begin{array}{ll}\text { Somatic } & \text { Psychologic } \\ \uparrow \text { fat mass (especially visceral) } & \uparrow \text { irritability and depressiveness } \\ \downarrow \text { free fat mass } & \downarrow \text { energy } \\ \downarrow \text { muscle mass, strength and endur- } & \downarrow \text { libido and erections (ED) } \\ \begin{array}{l}\text { ance } \\ \downarrow \text { bone mineral density }\end{array} & \downarrow \text { cognitive functions } \\ \downarrow \text { hair growth and skin thickness } & \downarrow \text { quality of sleep }\end{array}$

Ryder, 2004). Commonly, the domain for EF is preferred including questions $1-5$ and 15 addressing the last 4 week period. The presence of ED is assumed if the score is less than 26 points. ED is stratified into severe $<11$, moderate $<16$, moderate to mild $<21$ and mild $\leq 25$ points. Sexual Encounter Profile Question-2 (SEP2) - have you been able to insert your penis into your partner's vagina? Sexual Encounter Profile Question-3 (SEP3) - Was you erection long enough to allow successful sexual encounter? Global Assessment Question (GAQ) - Do you think that the treatment improved your erection? (answer yes/no). This question is asked after the use of the drug.

2. The differential diagnosis is based on carefully collected patient history which may help significantly the orientation for the main causes of the ED in the particular case.

- In DM the origin for ED is organic in most cases but it should not be forgotten that in young men with diabetes with shorter duration psychogenic component may prevail. It should be remembered that psychogenic aspects are present in different degree in all patients independent of the stage of the disease. When further psychological support and therapy is planned, the patient is best referred to the appropriate specialist.

- Patients with DED need more common vascular investigations with Doppler for diagnostic reasons and therapeutic options.

- More sophisticated investigations like RigiScan - a device for ambulatory monitoring of the spontaneous nocturnal tumescences usually 3-5 times during the night, typically during REM sleep, based on evaluation of 2 circumferent pneumatic sensors placed around the penis during the night, might be helpful on some occasions. The simple stamp-test could also be used if doubt exists about nocturnal tumescences. The pharmacological test with intracavernosal injections of vasoactive drugs and Doppler evaluation of the pre- and post-aplication bloodflow, with or without visual sexual stimulation, is usually performed in the medical office.

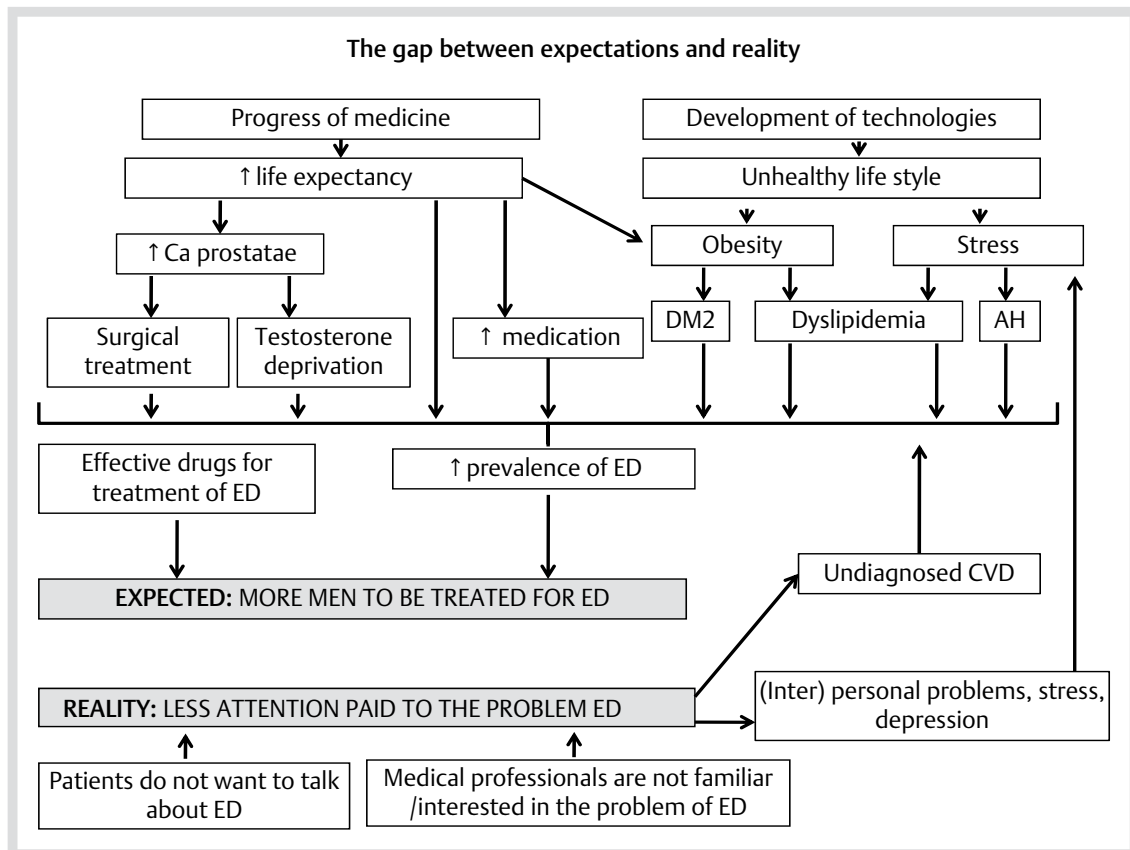

Fig. 6 The gap between expectations and reality. (modified from Kamenov, 2013). 
- Neurologically focused history and tests are of special interest in DED. It should be mentioned that the absence of neurological symptoms and signs does not necessarily mean the absence of DN. On the contrary, some symptoms and signs caused by other neurological diseases are commonly attributed to DN because medical specialists are expecting the patient to have this diabetic complication. $\mathrm{DN}$ is a diagnosis per exclusionem. The most common initial nerve damage usually affects different sensory modalities and autonomic functions. Simple sensory diagnostic devices may be applied for evaluation of sensory function like the128-Hz Rydel-Seiffer tuning fork (vibration perception), Semmes-Weinstein 5.07 (10g) monofilament (pressure perception), thermal discriminator (thermal perception), etc., as well as autonomic tests (Neuropad for sudomotor function). They could be easily used in the everyday clinical practice in the community for the improvement of diagnostic sensitivity (Kamenov et al., 2010; Kamenov, Traykov, 2012b; Manes et al., 2014). Special neurological tests may also be necessary in patients with ED (Diemont, Meuleman, 1997).

- The reported very high prevalence of low testosterone (T) levels in diabetic men makes the exclusion of hypogonadism a more important initial diagnostic step compared to non-diabetic men. Omitting $\mathrm{T}$ determination at this point of the evaluation of DED may cause further ineffectiveness of pro-erectogenic medications, loss of confidence and disappointment and worsening of the treatment prognosis and increasing frustration. Early morning total T levels below $8 \mathrm{nmol} / \mathrm{L}$, confirmed on a consecutive visit, associated with corresponding symptoms ( $\odot$ Table 1 ) usually require testosterone supplementation after exclusion of the respective contraindications. Levels above $12 \mathrm{nmol} / \mathrm{L}$ usually are not considered as an indication for TRT. If the patient has total T levels in the grey zone $(8-12 \mathrm{nmol} / \mathrm{L})$ the case needs further evaluation and determination of free $\mathrm{T}$. In detail the diagnostic approach for hypogonadism is described elsewhere (Wang et al., 2009). It should not be forgotten that decrease of $\mathrm{T}$ might be caused by different endocrine (hypothalamic, pituitary, testicular, etc.) and other diseases and drugs, which makes the full set of differential diagnosis for hypogonadism necessary. Prolactinomas and other pituitary or hypothalamic tumors in men cause typically hypogonadotropic hypogonadism and because of the olygosymptomatic presentation are commonly diagnosed at the advanced stage of macrotumors. A common cause for hypogonadism is obstructive sleep apnoea. The diagnosis is suspected from the history and questionnaires for night apnoea periods and daily sleepiness, and confirmed by polysomnography. Treatment with mechanical devices (CPAP, BPAP) leads to improvement of metabolic, hormonal, sexual, and QoL indices (Reinhardt et al., 2004). Haemochromatosis is one the most common genetic disorders with homozygote frequency of $0.3-0.5 \%$ and a carrier frequency of $6.7-10 \%$ (Gluckman 1996). It may cause DM and hypogonadism with primary (testicular involvement), secondary (pituitary), tertiary (hypothalamus) origin or a combination of them. Treatment, particularly at the earlier stages, may improve the hormonal problems (Siemons \& Mahler 1987; Angelopoulos et al., 2007).

\section{Treatment Options for DED \\ $\nabla$}

The already described mixed pathogenesis of DED requires a complex treatment which can be divided into general and specific measures.

The general measures include the improvement and control of the main pathogenetic factors leading to DED. The therapeutic approach does not differ from the currently accepted options for reaching the appropriate for the particular patient targets for blood glucose, lipids and blood pressure control as well as the cessation or limitation of unhealthy lifestyle habits like smoking, alcohol overconsumption, immobilization, stress, use of recreational drugs, etc.

Although the data about the beneficial effect of life style modification on ED are limited diet and physical activity changes should always be recommended for diabetic men with ED (Giugliano et al., 2010). Nevertheless studies investigating the effect of weight loss on DED are scarce (Stoian et al., 2014). The Look AHEAD (Action for Health in Diabetes) trial examined 1-year changes in EF, measured by the IIEF in 372 overweight/obese men aged 45-74 with DM2 randomly assigned to diabetes support and education or to intensive lifestyle intervention involving group and individual sessions to reduce weight and increase physical activity. At 1 year, the intensive group lost a greater percent of initial body weight (9.9 vs. $0.6 \%$ ), had greater improvements in fitness (22.7 vs. 4.6\%) and EF improved more (17.3 \pm 7.6 at baseline; $18.6 \pm 8.1$ at 1 year) than the control group (18.3 \pm 7.6 at baseline; $18.4 \pm 8.0$ at 1 year); $P=0.04$ and after adjusting for baseline differences $P=0.06$. According to the results of the $82 \%$ of men who finished the study the authors concluded that in this sample of older overweight/obese diabetic men, weight loss intervention was mildly helpful in maintaining $\mathrm{EF}$ (Wing et al., 2010).

Strict glycemic control is the cornerstone in the treatment of DM and prevention of its complications like DED. Poor control increases the risk for ED 2-5-fold compared to good control (Fedele et al., 1998; Klein et al., 2005). C-C. Lu et al., (2009) concluded in a study including 792 subjects with $83.6 \%$ of them having ED and $43.2 \%$ - severe ED that better glycemic control probably would reduce the prevalence of ED and its severity among the younger men with DM2, but aging is the major determinant for ED risk for the older group (Lu et al., 2009). Although new options are proposed (Hidmark et al., 2014), until now the results of pathogenetic treatment of DN have been generally disappointing, most probably because of the late initiation of the treatment. There are some exceptions from this non-optimistic conclusion like alpha-lipoic acid (review in Ziegler 2006; Boulton et al., 2013), and benfothiamine (Stracke et al., 2008).

The specific measures include the psychotherapy, oral treatment, intracavernosal injections and intraurethral application of PgE1, vacuum constrictor devices and penile implants. Summarizing the results in the literature it should be mentioned that:

1. There are not many studies designed wich focus on diabetic patients. Usually diabetics are sub-groups of larger patient populations. In some trials DM is even an exclusion criterion.

2. In most series diabetes (type, duration, control, etc.) and its macro- and microangiopathic complications including DN (presence, stage and treatment) are not described in detail.

3. In most cases oral treatment should be applied in the highest dose - sildenafil $100 \mathrm{mg}$, vardenafil $20 \mathrm{mg}$, tadalafil $20 \mathrm{mg}$, avanafil $200 \mathrm{mg}$, udenafil $200 \mathrm{mg}$, mirodenafil $100 \mathrm{mg}$. 
4. The effectiveness of the treatment in diabetic men is lower compared to non-diabetic (Price, Hackett, 2008). This difference is even underestimated because commonly poor glycemic control is an exclusion criterion at enrollment in the randomized clinical trials (RCT).

5. Patients with DED require more often switching to a higher line of treatment like intracavernosal injections, vacuum constrictor devices and implants, compared to healthy men.

6. Vascular reconstruction operations for ED are very rarely performed in diabetic patients.

\section{Psychological aspects of ED in DM}

Although there is a growing number of studies on the association between DED and psychological factors, the dominant scientific interest is focused on the organic pathology of DED. Some authors draw attention to the individual and marital pathology in diabetic men and the significance of psychological dimensions on the sexual impact of this illness (Siddiqui et al., 2012). ED is associated with higher levels of diabetes-specific health distress and worse psychological adaptation to DM, which in turn worsens metabolic control (Berardis et al., 2002). Diabetic men are more likely to consider their ED to be severe and permanent, compared with non-diabetic (Eardley et al., 2007). ED contributes to poorer overall quality of life in diabetic patients (Avasthi et al., 2011)

\section{PDE-5 inhibitors}

A new era in "erectology" began about 15 years ago with the introduction of the first inhibitor of PDE-5 - sildenafil. The members of this group of drugs inhibit the main PDE isoform in the cavernosal smooth muscle - type 5 responsible for the degradation of cGMP (Wallis et al., 1999) whose level increases and leads to improvement of the erection. Later PDE-5 inhibitors vardenafil, tadalafil and avanafil - have higher specificity to the target iso-enzyme (Saenz de Tejada et al., 2001a). Further avanafil and udenafil were also introduced on the market. Currently available PDE-5 inhibitors are very effective and safe and represent the first line therapy for treatment of ED, including DED, although less effective in diabetic men (Ng et al., 2002; PadmaNathan, 2003; Goldstein et al., 2003). Only 56\% of DM2 patients respond to PDE5, compared to $87 \%$ response in normal patients (Rendell et al., 1999). Even when a good response to treatment has been reported initially in DM2 patients, the effect is not sustainable overtime. After 1 year of treatment of men with DED, IIEF scores reverted to baseline values (Penson et al., 2003).

\section{Sildenafil}

Sildenafil is the most studied PDE-5i with an enormous data base. It has been successfully used in doses 25,50 and $100 \mathrm{mg}$ in the general population as well as in difficult-to-treat subgroups, particularly in DED. In one of the first trials - multicenter, randomized, double-blind, placebo-controlled study (RCT) 268 men with DED were randomized to sildenafil in a flexible escalating dose or placebo for a period of 12 weeks. In the active arm $56 \%$ of the patients had improvement of erections compared to $10 \%$ on placebo (Rendell et al., 1999).

Sildenafil has also been shown to be effective vs. placebo in DM1 patients. Significant improvements in the ability to achieve erections evaluated by IIEF (35.7 vs. $19.9 \%$ ) and to maintain erections (68.4 vs. $26.5 \%$ ), improved erections with treatment (GAQ 66.6 vs. $28.6 \%$ ), and successful attempts at intercourse (63 vs. $33 \%$ ) were reported (Stuckey et al., 2003).
In a RCT a total of 282 men were randomized to fixed-dose sildenafil or placebo. A significant improvement from baseline in IIEF Q3 (55 vs. 29\%) and IIEF Q4 (61 vs. 25\%) lead to the conclusion that sildenafil is a moderately effective treatment for ED in men with diabetes. The response rate was lower and cardiovascular events were higher than previously reported in non-diabetic patients (Safarinejad, 2004).

Sildenafil has been investigated for potential benefits in different diabetic areas. After one dose of $50 \mathrm{mg}$ an improvement of cerebrovascular reactivity, assessed using breath holding-hyperventilation test with trans-temporal ultrasound examination on the middle cerebral artery, was observed in diabetic, but not in nondiabetic men (Al-Amran et al., 2012). A. Burnett et al. (2009) evaluated the changes of biomarkers of vascular function serum cGMP, 8-isoprostane, IL-6 and IL-8 in men with DM2 with ED after use of sildenafil for 12 weeks (Burnett et al., 2009). They concluded that short-term continuous sildenafil treatment causes improvement in systemic endothelial function remaining for a period after its discontinuation. However, they did not mentioned any influence of this treatment on systemic oxidative stress or inflammation, or a long-term beneficial effect on EF. Grover-Páez et al. (2007) determined the levels of hs-CRP, microalbuminuria, homocysteine, $\mathrm{HbA} 1 \mathrm{c}$ and $\mathrm{EF}$ at baseline and after 30 days sildenafil $50 \mathrm{mg}$ daily or placebo. Men on sildenafil had a significant decrease of microalbuminuria vs. baseline $(p<0.01)$ and vs. placebo $(\mathrm{p}<0.02)$ and of $\operatorname{HbA1c}(\mathrm{p}<0.01$ and $\mathrm{p}<0.01$ respectively) (Grover-Páez et al., 2007). To evaluate the endothelial function 24 DM2 men were randomized to daily sildenafil $50 \mathrm{mg}$ or placebo for 10 weeks. At the end of the trial, those who received sildenafil had significantly improved erectile rigidity as captured by IIEF-5 ( $\mathrm{p}<0.001)$ and increased endothelial function via brachial artery flow-mediated dilation $(\mathrm{p}<0.01)$ (Deyoung et al., 2012).

\section{Tadalafil}

Tadalafil is an effective drug for treatment of ED of different severity and etiology. The most important difference compared to other available currently approved PDE-5 inhibitors is its long half-life (17.5) hours allowing (1) a long-lasting clinical effect of $36 \mathrm{~h}$ by on demand dosing with 5,10 or $20 \mathrm{mg}$, and (2) full diurnal therapeutic coverage by daily use in lesser dose (2.5 and $5 \mathrm{mg}$ ). Besides the evidence in the general population (Brock et al., 2002; Carson et al., 2004) the drug has been successfully used in difficult-to-treat patients with severe organic ED (Carson et al., 2005), DED (Saenz de Tejada et al., 2002; Fonseca et al., 2004), after radical prostatectomy (Carson et al., 2005; Montorsi et al., 2004) or radiation therapy (Incrocci et al., 2007). Tadalafil 10 and $20 \mathrm{mg}$ on demand resulted in 56 and $64 \%$ improvement of the erections compared to $25 \%$ in the placebo arm in a study with 191 diabetic men (Saenz de Tejada et al., 2002). Based on the significant benefit of low dose daily tadalafil (McMahon, 2004; Porst et al., 2008) the FDA approved this regimen in 2008. Tadalafil $5 \mathrm{mg}$ once daily is used also for lower urinary tract symptoms suggestive of benign prostatic hyperplasia (Porst et al., 2013).

In the diabetic arm (726 men with DED with minimal duration of 3 months) of the randomized crossover, open study with 4262 patients from 392 centers in 14 European countries The Scheduled Use vs. on-demand Regimen Evaluation (SURE) study tadalafil $20 \mathrm{mg}$ was used regularly 3 times a week irrespective of sexual activity or on demand (Buvat J et al., 2006). The patients were divided into 2 groups according to the used regimen and 
after a 5-6 weeks period the 2 arms were crossed using the alternative dose regimen for the same period of time. Regarding $\mathrm{DM}$, patients were considered having type 1 or 2 according to current insulin use and the age of onset of DM - before or after 40 years of age with no pre-selection for diabetic complications. At the end point on both regimens, the mean IIEF EF domain score was 22 , and $>40 \%$ of the patients had a normal EF domain score ( $\geq 26$ ). The proportion of "yes" responses was $\geq 73 \%$ for SEP2 (penetration), $\geq 58 \%$ for SEP3 (successful intercourse), $>46 \%$ for SEP4 (hardness of erection), and $\geq 45 \%$ for SEP5 (overall satisfaction). Efficacy was maintained up to $36 \mathrm{~h}$ post-dosing. More than $70 \%$ of sexual attempts while on the 3-times-per-week regimen and approximately $50 \%$ of the attempts with on-demand treatment occurred $>4 \mathrm{~h}$ post-dosing. Treatment preference was $57.2 \%$ for on demand and $42.8 \%$ for 3 times per week. The authors concluded that tadalafil, when taken on demand or 3 times per week, is efficacious and safe in men with DED.

Schulman et al. (2004) studied the differences in effectiveness of the fixed dose tadalafil over time (Schulman et al., 2004). They combined the data from five12-week RCTs including 3 groups of 308,321 and 258 men on placebo, 10 and 20 mg tadalafil respectively. The very first dose lead to significant improvement of SEP2 - 47, 74, 79\%; SEP3 - 31, 56, 67\% and SEP5 (satisfied overall with their sexual experience) $-15,36,47 \%$ respectively. Later on the effect increased reaching a plateau of $95 \%$ (SEP2), $90 \%$ (SEP3), and $81 \%$ (SEP5) between the $4^{\text {th }}$ and $8^{\text {th }}$ dose.

In a meta-analysis of 12 RCTs with tadalafil Fonseca et al. (2004) included 637 men of mean age 57 years with DM and mean baseline IIEF 12.6 (Fonseca et al., 2004). The use of tadalafil 10 or $20 \mathrm{mg}$ lead to an improvement of 7.4 points vs. 0.9 points in the placebo group. In men with DM $53 \%$ of the sexual attempts were successful vs. $22 \%$ in the placebo group. Baseline IIEF showed a negative correlation with $\mathrm{HbA1c}$, but the response to tadalafil treatment was not related to the glycemic control, type of treatment or previous use of sildenafil. No analysis was made on the pathogenic factors for ED. Comparison of this population with 1681 men of mean age 56 years with ED (baseline IIEF=15) without diabetes demonstrated more severe ED in DM but independently equal therapeutic effect to tadalafil.

\section{Vardenafil}

Vardenafil is a powerful PDE5 inhibitor whose efficacy and tolerability at doses 5, 10 and $20 \mathrm{mg}$ were shown in RCTs including large populations of men with ED (Porst et al., 2001; Hellstrom et al., 2002; Hatzichristou et al., 2004), and men presenting difficult-to-treat groups like DM, after prostatectomy etc. (Goldstein et al., 2003; Brock et al., 2003). The reliability of vardenafil was determined in a retrospective analysis of 2 clinical studies showing an increased probability for penetration, maintenance of erection and higher general satisfaction compared to placebo. Most of the patients who responded to the first dose of vardenafil reported success during the whole 12 -week treatment period (Montorsi et al., 2004). In one open study with 398 non-preselected men the efficacy and tolerability of vardenafil used at initial dose of $10 \mathrm{mg}$ and titrated to 5 or $20 \mathrm{mg}$ were investigated (Potempa et al., 2004). At the end of the 10-week therapeutic period an improvement in EF domain of IIEF from 13.9 to 25.9 points, successful penetration SEP2 in $89 \%$, maintenance of erection SEP3 in 78\% and general satisfaction of the treatment (GAQ) in $92 \%$ were reported.
Goldstein et al. (2003) conducted in the USA and Canada a multicenter RCT with 452 men with DM1 and DM2 with HbA1c $<12 \%$ (Goldstein et al., 2003). Patients were randomized in 3 groups vardenafil 10 or $20 \mathrm{mg}$ or placebo over a 12 week period. The drug was taken $1 \mathrm{~h}$ before intercourse no more than once a day. After the end of this period the patients received 10 or $20 \mathrm{mg}$ vardenafil for another 12 weeks. Treatment efficacy was assessed using IIEF, GAQ, SEP2 and SEP3. Sub-analyses of the data was made according to the baseline severity of ED, HbA1c $(<6,<8$ and $>8 \%$ ), and dose-response effect. Special focus was placed on the registration of possible side effects. At the end of the trial for the different doses vardenafil 57 and $72 \%$ of the men reported an improvement in EF according to GAQ compared to $13 \%$ improvement in the placebo group. On the twelfth treatment week IIEF increased by 19.0 points. Successful penetration (SEP2) was achieved by $64 \%$, and successful coitus (SEP3) by $54 \%$ of men. The results of this study were summarized in 3 major conclusions: (1) Vardenafil has a favorable dose-dependent treatment profile on DED. (2) The efficacy of vardenafil is present irrespective of the baseline severity of ED and glycemia. (3) The drug has no serious side effects and has very good tolerability. No disturbances of color vision were reported.

Patient satisfaction with the treatment for ED is critical for his long term compliance (Dean et al., 2006). In one international trial with 3291 men with ED $47 \%$ of them pointed the "constant efficacy" as the most important feature of the treatment (Eardley et al., 2003; Meuleman et al., 2003). This is extremely important in men with DM, who report their ED to be severe and permanent, seek medical help more often and are more prone to discontinuation of the treatment because of an unsatisfactory result, than are men without diabetes (Eardley et al., 2007). Most of the above mentioned research suggests that responsiveness to PDE5i drugs increases with sequential dosing from initiation; 8 doses are generally considered an adequate trial of therapy to establish efficacy. The effect of the first intake of a PDE5 inhibitor is a prognostic factor for its treatment efficacy. It can be stated that the initial success and further reliability of the treatment for ED are crucial for patient satisfaction with the treatment that directly affects compliance. L.Valiquette et al. (2005) evaluated the efficacy of the first intake of $10 \mathrm{mg}$ vardenafil vs. placebo in non-selected population of 600 men of mean age $54 \pm 11$ years (20-79), of whom $30 \%$ had hypertension, $15 \%$ DM and $16 \%$ dyslipidemia (Valiquette et al. (2005)). Baseline EF domain of IIEF is $14.6 \pm 5$ points, and ED duration about $5.6 \pm 5.2$ years. Efficacy regarding SEP2 is $87 \%=520$ of total 600 men reported successful penetration and $85 \%$ of them maintained their erection to the end of the intercourse (SEP3), which equals the $74 \%$ success of the first intake of vardenafil regarding SEP3 in the general population. Although head-to-head comparisons are scarce the data about the effectiveness of the PDE-5 inhibitors in diabetic men suggest a similar degree. Recently, we compared the effect of the first intake of tadalafil $20 \mathrm{mg}$ and vardenafil $20 \mathrm{mg}$ in men from the difficult-to-treat group with DED and proven DN (Kamenov, 2011). To synchronize the therapeutic windows, sexual intercourse should have been initiated in the interval of 1-6h after the drug intake. In this time frame the effectiveness (IIEF-EF, SEP2, SEP3, GAQ) of both medications was comparable.

\section{Avanafil}

Avanafil was recently approved by the US Food and Drug Administration (2012) and European Medicine Agency (2013) for the management of ED. It was studied in over 1300 patients during 
clinical trials, including patients with DM and those who had undergone radical prostatectomy, and was found to be more effective than placebo in all men who were randomized to the drug. The medication was studied with on-demand dosing as 50,100 , or $200 \mathrm{mg}$ that may occur after food and/or alcohol. Avanafil has a very quick onset of action and higher specificity for phosphodiesterase type 5 vs. other phosphodiesterase subtypes (Burke, Evans, 2012).

In a 12-week, multicenter RCT 390 men with DED were randomized 1:1:1 to receive avanafil 100 or $200 \mathrm{mg}$, or placebo. Compared with placebo IIEF-EF domain, SEP2 and SEP 3 improved with both doses avanafil - $100 \mathrm{mg}(\mathrm{P} \leq 0.002)$, and $200 \mathrm{mg}$ $(\mathrm{P}<0.001)$. The authors concluded that avanafil was safe and effective for treating ED in men with diabetes and was effective as early as $15 \mathrm{~min}$ and more than $6 \mathrm{~h}$ after dosing. The adverse events seen with avanafil were similar to those seen with other PDE-5 inhibitors (Goldstein et al., 2012).

In a 52-week open-label extension phase of two 12-week RCTs 686 patients with mild to severe ED with or without diabetes were assigned to avanafil $100 \mathrm{mg}$, but could request $200 \mathrm{mg}$ (for increased efficacy; 100/200-mg group) or $50 \mathrm{mg}$ (for improved tolerability). SEP2 and SEP3 success rates improved from 44 to $83 \%$ and from 13 to $68 \%$ (100-mg group) and from 43 to $79 \%$ and from 11 to $66 \%$ (100/200-mg group), respectively. Mean IIEF-EF domain scores improved from 13.6 to 22.2 (100-mg group) and from 11.9 to 22.7 (100/200-mg group). Based on the the longterm tolerability and improvement in sexual function, coupled with rapid onset, the authors concluded that avanafil is well suited for the on-demand treatment of ED (Belkoff et al., 2013).

Recently, Yilmaz et al. (2014) injected intracavernosally $1 \mu \mathrm{M}$ avanafil for 10 weeks in rats with streptozotocin induced diabetes. Avanafil partially restored the diminished intracavernosal pressure responses in diabetic rats. After the application of different stimuli on corpus cavernosal strips from the diabetic group the relaxation responses were enhanced and contractile responses diminished. The authors suggested that intracavernosal administration of avanafil might also be beneficial for the treatment of ED in patients with DM2 (Yilmaz et al., 2014).

\section{Udenafil}

Udenafil is a potent novel PDE-5 inhibitor approved for use in Korea. Udenafil has a T max of 1.0-1.5 h and a T $1 / 2$ of 11-13 h. Therefore, both on-demand and once-daily use of udenafil have been reported. Udenafil's efficacy and tolerability in doses 100 or $200 \mathrm{mg}$ have been evaluated in several studies, and recent and continuing studies have demonstrated udenafil's promise in both dosing regimens. Presently, tadalafil is the only FDAapproved drug for daily dosing, but udenafil can be used as a once-daily dose for erectile dysfunction patients who cannot tolerate tadalafil due to phosphodiesterase subtype selectivity (Kang, kim, 2013). Recently Park et al. (2014) proved the equal efficacy and safety of $200 \mathrm{mg}$ on-demand or $50 \mathrm{mg}$ once-daily dosing udenafil for 8 weeks on IIEF, SEP Q2 and Q3, GAQ and vascular endothelial markers in a multi-center, randomized, open-label, parallel-group, 12-week study with 161 DM2 patients. The authors concluded that both regimens were welltolerated with flushing and headache being the most frequent adverse events and further studies are needed to assess the effect of daily udenafil treatment in diabetic patients (Park et al. (2014)).
Udenafil as an on-demand or once-daily dose is effective and tolerable, but more studies are needed in patients of other ethnicities and with comorbid conditions such as DM, hypertension, and benign prostate hyperplasia (Kang, Kim, 2013).

In a multicenter, fixed-dose RCT with 174 Korean patients with DED randomized to placebo, 100 or $200 \mathrm{mg}$ of udenafil for 12 weeks were evaluated by IIEF (Q3 and Q4), the rate of achieving normal EF (IEEF $\geq 26$ ), SEP2, SEP3, and GAQ. Compared with the placebo, patients receiving both doses of udenafil showed statistically significant improvements in the IIEF-EFD score. However, a statistically significant difference was not observed between the udenafil 100 and $200 \mathrm{mg}$ groups. Similar results were observed in the comparison of Q3 and Q4 of IIEF, SEP diary, and GAQ. The percentages of subjects experiencing at least one adverse event related to the study drugs were 3.6, 15.8, and $22.4 \%$ for the placebo, udenafil 100 and $200 \mathrm{mg}$ groups, respectively. Major adverse events were flushing, headache, nausea, and conjunctival hyperemia. The study concluded that udenafil was significantly effective for the treatment of ED, demonstrating significant improvement in EF in patients with DM. The incidence of adverse events was relatively low and well tolerated in patients with DM (Moon du et al., 2011).

\section{Mirodenafil}

A multicenter, parallel-group, fixed-dose RCT was conducted with 112 subjects who were randomized to either placebo or mirodenafil $100 \mathrm{mg}$ on demand for 12 weeks. The active group showed significantly greater change from the baseline compared with the placebo group in the following indicators: IIEF-EF (9.3 vs. $1.4, \mathrm{P}<0.0001)$, IIEF Q3 (1.7 vs. $0.4, \mathrm{P}<0.0001)$ and Q4 (1.7 vs. $0.3, \mathrm{P}<0.0001$ ), SEP2 (82.0 vs. $55.2 \%, \mathrm{P}=0.0003$ ), SEP3 (68.9 vs. $22.3 \%, \mathrm{P}<0.0001$ ), GAQ (76.9 vs. $19.1 \%, \mathrm{P}<0.0001)$. Normal EF domain scores $(\geq 26)$ at the study end were achieved by $32.7 \%$ and $9.4 \%$ in the mirodenafil and placebo groups respectively $(P=0.0031)$. As for the Life Satisfaction Checklist scores, the mirodenafil group showed significantly greater improvements in sexual life and partner relationship than the placebo group. Most treatment-associated AEs were mild that resolved spontaneously. The conclusion of this study was that mirodenafil is an effective and well-tolerated agent for the treatment of diabetic patients with ED in Korea (Park et al., 2010).

\section{Adverse events of PDE-5 inhibitors}

The tolerance and safety of PDE-5 inhibitors is very good. Recent studies have even shown several pleiotropic beneficial effects of PDE-5 inhibitors in patients with CAD, hypertension, heart failure, pulmonary arterial hypertension, DM and Raynaud's phenomenon (recent reviews in Chrysant, 2013, Giagulli et al., 2013). Side effects and interactions of PDE-5 inhibitors with other drugs have been minimal, with the exception of their coadministration with nitrates, which could lead to severe vasodilation and hypotension and therefore, their co-administration is prohibited. A Cochrane Database Report analyzing the randomized placebo-controlled studies did not find any lethal case in men with DED. Only in one study have cardiovascular adverse events been reported. The most common side effects (with a decreasing rate) are: headache, flush, respiratory tract complaints and flu-like symptoms, dyspepsia, myalgia, vision disturbances and back pain (Vardi, Nini 2007).

More concise data about the adverse events are available for the "older" PDE-5 inhibitors. After a systematic review and metaanalysis (Tsertsvadze et al., 2009) the following conclusions 


\begin{tabular}{|c|c|c|c|c|c|}
\hline Drug & Dose (mg) & $t_{1 / 2}(h)$ & Frequency & Advantages & Side effects \\
\hline sildenafil & $25,50^{*}, 100$ & 4.6 & \multirow{6}{*}{$\begin{array}{l}\text { On } \\
\text { demand or } \\
\text { daily }\end{array}$} & \multirow{6}{*}{$\begin{array}{l}\text { safe; available on } \\
\text { demand as well as } \\
\text { continuous low dose } \\
\text { (tadalafil } 2.5 \text { and } 5 \mathrm{mg} \text { ) }\end{array}$} & \multirow{6}{*}{$\begin{array}{l}\text { headache, myalgia, back pain, } \\
\text { blurred vision, facial flushing, } \\
\text { nasal congestion, dizziness }\end{array}$} \\
\hline tadalafil & $2.5,5,10,20$ & $17-21$ & & & \\
\hline vardenafil & $2.5,5,10^{*}, 20$ & $4-5$ & & & \\
\hline avanafil & $50,100,200$ & $5-10$ & & & \\
\hline udenafil \# & 100,200 & $11-13$ & & & \\
\hline mirodenafil \# & 50,100 & 2.5 & & & \\
\hline
\end{tabular}

$t_{1 / 2}$ : plasma half-life time; h: hours; * also available in orodispersable formulation (supralingual); \#not approved in Europe (Gareri et al., 2014; Park et al., 2014; Kang, kim, 2013; Ryu et al., 2013)

about (1) vs. placebo and (2) head-to-head comparisons were made: (1) A greater proportion of men treated with PDE-5i than placebo had at least 1 adverse event. The most commonly reported adverse events were headache, flushing, rhinitis, and dyspepsia. Other reported events were visual disturbances, myalgia, nausea, diarrhea, vomiting, dizziness, and chest pain. In general, these events were mild to moderate and were transient. Serious adverse events were reported in fewer than $2.0 \%$ of participants, and the incidence did not differ between PDE-5 inhibitor recipients and placebo recipients. (2) Differences in the incidence of any adverse events among men treated with sildenafil (range, 24.0-34.0\%), tadalafil (range, 28.0-35.0\%), and vardenafil (27.0\%) were not statistically significant. Discontinuation due to adverse effects ranged from $0.5-3.8 \%$ during tadalafil treatment, $0.5-3.8 \%$ during sildenafil treatment, and $1.0 \%$ during vardenafil treatment. The frequency of specific adverse events (headache, flushing, dyspepsia, and nasal congestion) seemed similar among treatments. Data about the currently available PFE-5 inhibitors worldwide are presented on $\bullet$ Table 2. In real non-responders to a particular PDE-5 inhibitor the following could be attempted: (1) test for low testosterone level (if not already done at the initiation of the treatment) and if hypogonadal - TRT should be started (more details in Nieschlag et al., 2006); (2) metabolic optimization (also an earlier target); (3) escalation of the dose of the PDE-5 inhibitor ad maximal; (3) change of the PDE-5 inhibitor; (4) daily dosing of tadalafil; (5) second and third line treatment.

\section{Second and third line treatment options}

Second line treatment options include intracavernosal injections of individual or combined (bimix, trimix) drugs and vacuum constrictor devices. Third-line therapy are the penile prostheses (implants).

\section{Intracavernosal injections (ICI)}

Since 1983, ICI has become a staple therapeutic option and high success rates have been reported (Coombs et al., 2012). ICI of vasoactive drugs - prostaglandin E1 (also used transurethral), phentolamine, vasoactive intestinal peptide (VIP), papaverine. PGE1 stimulates adenylate cyclase, thereby increasing levels of cAMP, which results in smooth muscle relaxation and vasodilatation. Erection appears after $5-15 \mathrm{~min}$ and lasts for a period that depends on the dose injected. The patient should be enrolled in an office-based training programme (requiring 1 or 2 visits) to learn the correct injection procedure (Phé, Rouprêt, 2012). Intracavernosal injections remain safe, and a highly effective treatment option in men with DED (Redrow et al., 2014). The efficacy rate is approximately $70 \%$, with reported sexual activity after $94 \%$ of injections, and satisfaction rates are high (Moore, Wang, 2006). However, dropout rates of $41-68 \%$ have been reported, with most dropouts occurring within the first
2-3 months (Vardi et al., 2000). Complications with intracavernous alprostadil include penile pain ( $50 \%$ of patients after $11 \%$ of injections), prolonged erections (5\%), priapism ( $1 \%$ ) and fibrosis (2\%) (Hatzimouratidis, Hatzichristou, 2005). Drug combinations such as alprostadil plus papaverine, a non-specific PDE inhibitor resulting in increased levels of cAMP and/or cGMP, and alprostadil plus phentolamine, a competitive antagonist of alpha-1 and alpha- 2 adrenoreceptors, may increase efficacy by up to $90 \%$.

\section{Vacuum constriction devices (VCDs)}

apply negative pressure to draw blood into the penis that is then retained by the application of a visible constricting band at the base of the penis. This method appears to be more acceptable to older patients (Levine, Dimitriou, 2001). There are few recognized complications with this low-cost treatment option for selected diabetic ED patients. It was reported that VCDs achieved satisfactory erections in more than $70 \%$ of diabetic men (Price et al., 1991). Recently, Sun et al. (2014) reported that combined use of sildenafil and VCD for 3 months significantly enhances erectile function, and is well tolerated by DM patients not responding to first-line sildenafil $100 \mathrm{mg}$ alone (Sun et al., 2014). Problems with VCDs include pain from the constriction ring, lack of spontaneity, decrease in the quality of orgasm and ejaculatory discomfort. In addition, up to $30 \%$ of patients discontinue use as the result of inadequate rigidity, penile pain, failure to ejaculate and the appearance of the penis while using the device (Price et al., 1991; Sidi et al., 1990).

\section{Penile implants}

When pharmacotherapy fails, surgical implantation of a penile prosthesis may be considered. Penile implants provide a predictable and reliable erection, and have the highest satisfaction rate among both patients and their partners of all the available treatments for waning erections (Phé, Rouprêt, 2012; Redrow et al., 2014). Prostheses are either malleable (semirigid) or inflatable (2- or 3-pieces). In a study of 224 Chinese men patient satisfaction was higher $(\mathrm{P}<0.05)$ in the 3-pieces inflatable than in the malleable prosthesis group (Song et al., 2013). Men with DM are more likely to require more aggressive treatments for ED. In a recent study including 19236 diabetics it was shown that they were more than $50 \%$ more likely to be prescribed secondary ED treatments, and more than twice as likely to undergo penile prosthesis surgery compared to non-diabetics (Walsh et al., 2014). DED is among the 2 main reasons for implantation of an implant. Segal et al. (2014) developed a prediction tool based on a patient's clinical history to determine likelihood of ultimately receiving a penile prosthesis (Segal, 2014). Inclusion criteria were 18 years of age with 1 year of continuous enrollment at the first diagnosis of ED. Analyzing the data from the Commercial $(\mathrm{N}=310303)$ and Medicare $(\mathrm{N}=74315)$ supplemental data- 
bases they found approximately $1 \% / \mathrm{N}=3928$ patients of the dataset's population $(0.78 \% / 2405$ and $2.05 \% / 1523$, respectively) underwent penile prosthesis implantation during the study period. Factors with the greatest predictive strength of penile prosthesis implantation included prostate cancer diagnosis (relative risk: 3.93, 2.29; 95\% CI, 3.57-4.34, 2.03-2.6) and DM (2.31, $1.23 ; 2.12-2.52,1.1-1.37$ ) (both $\mathrm{P}<0.01$ ).

The 2 main complications associated with penile prostheses are mechanical failure ( $<5 \%$ after a 5 -year follow-up with the currently available 3-pieces prostheses) and infection. Since the introduction of a 3-pieces inflatable penile implant impregnated with the antibiotics minocycline and rifampin, there has been a significant reduction in infection rates and currently, the infection rate is $1 \%$ (Carson et al., 2011). The "no touch" enhancement to the surgical procedure further decreases the rate of infection to $0.46 \%$ (Eid et al., 2012). For non-impregnated implants, the infection risk rate is around 2.5\% (Montague et al., 2001). Some research has indicated that diabetics have an increased risk of infection vs. non-diabetics, but most studies observed no differences in infection rates (Wilson, Delk, 1995; Jarow, 1996; Wilson et al., 1998; Montague et al., (2001); Chung et al., 2013). A penile prosthesis infection may be either treated with explantation of the prosthesis with a possible delayed reimplantation or a salvage procedure with an immediate reimplantation of the prosthesis. In a total of 1557 patients treated with an explantation only $(82.7 \%)$ or salvage $(17.3 \%)$ comorbid diabetes did not independently affect the salvage rate of penile prosthesis infection (Zargaroff et al., 2014).

\section{Conclusions}

Due to its complex pathogenesis DED is more common and difficult for treatment compared to healthy men. Its presentation commonly precedes the clinical manifestation of vascular diseases in other arterial areas and might be a predictor for more serious micro-vascular problems. Therapeutic schemes for comorbidities like hypertension, dyslipidemia, pain relief, psychological problems, etc., should be composed carefully and harmonized in the aspect of metabolic syndrome and ED. Treatment of DED requires a team approach, with the very important participation of specialists in sexual medicine. The therapeutic approach includes correction of metabolic disturbances and possible hypogonadism. Although effective and safe medications already exist, very often DED is not adequately diagnosed and treated which leads further to aggravation of psychological and couple distress. In most cases the reason for this is the communicative problem - the physician does not ask and the patient does not share spontaneously the presence of DED. PDE-5 inhibitors are the first line therapy in DED. Switching to second and third line therapy - intracavernosal injections, vacuum constriction devices, and penile implants is more common in men with DED.

\section{Conflict of interest: None.}

\section{References}

1 Aaberg ML, Burch DM, Hud ZR et al. Gender differences in the onset of diabetic neuropathy. J Diabetes Complications 2008; 22: 83-87

2 Adegite A, Aniekwensi E, Ohihoin A et al. Perception about aetiology of sexual problems, health seeking behavior and treatment for sexual problems among type 2 diabetic men. 20 ${ }^{\text {th }}$ IDF World Congress, 18-22.10.2009, Montreal, Canada; P-1370, Book of abstracts p.462
3 Al-Amran FG, Zwain AA, Hadi NR et al. Autonomic cerebral vascular response to sildenafil in diabetic patient. Diabetol Metab Syndr 2012; 27; $4: 2$

4 Angelopoulos N, Papanikolaou G, Noutsou M et al. Glucose Metabolism, Insulin Secretion and Insulin Sensitivity in Juvenile Hemochromatosis. A Case Report and Review of the Literature. Exp Clin Endocrinol Diabetes 2007; 115: 192-197

5 Angulo J, González-Corrochano R, Cuevas P et al. Diabetes exacerbates the functional deficiency of NO/cGMP pathway associated with erectile dysfunction in human corpus cavernosum and penile arteries. J Sex Med 2010; 7 (2 Pt 1): 758-768

6 Arafa M, Eid H, El-Badry A et al. The prevalence of Peyronie's disease in diabetic patients with erectile dysfunction. Int J Impot Res 2007; 19: $213-217$

7 Avasthi A, Grover S, Bhansali A et al. Erectile dysfunction in diabetes mellitus contributes to poor quality of life. Int Rev Psychiatry 2011; 23: 93-99

8 Baba K, Yajima M, Carrier S et al. Effect of testosterone on the number of NADPH diaphorase-stained nerve fibers in the rat corpus cavernosum and dorsal nerve. Urology 2000; 56: 533-538

9 Bacon CG, Hu FB, Giovannucci E et al. Association of type and duration of diabetes with erectile dysfunction in a large cohort of men. Diabetes Care 2002; 25: 1458

10 Bartolini M, Giommi R, Forti G et al. Organic, relational and psychological factors in erectiledys function in men with diabetes mellitus. Eur Urol 2004; 46: 222-228

11 Basu A, Ryder RE. New treatment options for erectile dysfunction in patients with diabetes mellitus. Drugs 2004; 64: 2667-2688

12 Belkoff LH, McCullough A, Goldstein I et al. An open-label, long-term evaluation of the safety, efficacy and tolerability of avanafil in male patients with mild to severe erectile dysfunction. Int J Clin Pract 2013; 67: 333-341

13 Berardis GD, Franciosi $M$, Belfigli $M$ et al. Erectile dysfunction and quality of life in type 2 diabetic patients: A serious problem too often overlooked. Diabetes Care 2002; 25: 284-291

14 Bivalacqua TJ, Champion HC, Usta MF et al. RhoA/Rhokinase suppresses endothelial nitric oxide synthase in the penis: a mechanism for diabetes-associated erectile dysfunction. Proc Natl Acad Sci USA 2004; 101: 9121-9126

15 Bivalacqua TJ, Usta MF, Champion HC et al. Endothelial dysfunction in erectile dysfunction: role of the endothelium in erectile physiology and disease. J Androl 2003; 24 (Suppl 6): S17-S37

16 Bivalacqua TJ, Usta MF, Kendirci $M$ et al. Superoxide anion production in the rat penis impairs EF in diabetes: influence of in vivo extracellular superoxide dismutase gene therapy. J Sex Med 2005; 2: 187197

17 Boulton AJ, Kempler P, Ametov A et al. Whither pathogenetic treatments for diabetic polyneuropathy? Diabetes Metab Res Rev 2013; 29: 327-333

18 Brock G, Nehra A, Lipshultz LI et al. Safety and efficacy of vardenafil for the treatment of men with erectile dysfunction after radical retropubic prostatectomy. J Urol 2003; 170 (4, pt 1): 1278-1283

19 Brock GB, McMahon CG, Chen KK et al. Efficacy and safety of tadalafi 1 for the treatment of erectile dysfunction: results of integrated analyses. J Urol 2002; 168: 1332-1336

20 Bucala R, Tracey KJ, Cerami A. Advanced glycosylation products quench nitric oxide and mediate defective endothelium-dependent vasodilation in experimental diabetes. J Clin Invest 1991; 87: 432438

21 Burchardt T, Burchardt M, Karden J et al. Reduction of endothelial and smooth muscle density in the corpora cavernosa of the streptozotocin induced diabetic rat. J Urol 2000; 164: 1807-1811

22 Burke FP, Jacobson DF, McGree ME et al. Diabetes and sexual dysfunction in Olmsted County, Minnesota. J Sex Med 2006; 3 (Suppl 1): 19

23 Burke JP, Jacobson DJ, McGree ME et al. Diabetes and sexual dysfunction: Result from Olmsted county study of urinary symptoms and health status among men. The journal of urology 2007; 177: 14381442

24 Burke RM, Evans JD. Avanafil for treatment of erectile dysfunction: review of its potential. Vasc Health Risk Manag 2012; 8: 517-523

25 Burnett AL, Strong TD, Trock BJ et al. Serum biomarker measurements of endothelial function and oxidative stress after daily dosing of sildenafil in type 2 diabetic men with erectile dysfunction. J Urol 2009; 181: 245-251

26 Buvat J, van Ahlen $H$, Schmitt $H$ et al. Efficacy and safety of two dosing regimens of tadalafil and patterns of sexual activity in men with diabetes mellitus and erectile dysfunction: Scheduled use vs. ondemand regimen evaluation (SURE) study in 14 European countries. J Sex Med 2006; 3: 512-520 
27 Buyukafsar K, Un I. Effects of the Rho-kinase inhibitors, Y-27632 and fasudil, on the corpus cavernosum from diabetic mice. Eur J Pharmacol 2003; 472: 235-238

28 Carson CC $3^{\text {rd }}$, Mulcahy JJ, Harsch MR. Long-term infection outcomes after original antibiotic impregnated inflatable penile prosthesis implants: up to 7.7 years of follow-up. J Urol 2011; 185: 614-618

29 Carson CC, Rajfer J, Eardley I et al. The efficacy and safety of tadalafi l: an update. BJU Int 2004; 93: 1276-1281

30 Carson CC, Shabsigh R, Segal S et al. Efficacy, safety, and treatment satisfaction of tadalafi l versus placebo in patients with erectile dysfunction evaluated at tertiary-care academic centers. Urology 2005; 65: 353-359

31 Cartledge JJ, Eardley I, Morrison JF. Advanced glycation end-products are responsible for the impairment of corpus cavernosal smooth muscle relaxation seen in diabetes. B J U Int 2001; 87: 402-407

32 Chitaley K, Kupelian V, Subak L et al. Diabetes, obesity and erectile dysfunction: field overview and research priorities. J Urol 2009; 182 (6 Suppl): S45-S50

33 Chitaley $K$. Type 1 and type 2 diabetic-erectile dysfunction: same diagnosis (ICD-9), different disease? J Sex Med 2009; 6 (suppl): 262

34 Christ GJ, Lerner SE, Kim DC et al. Endothelin-1 as a putative modulator of erectile dysfunction: I. Characteristics of contraction of isolated corporal tissue strips. J Urol 1995; 153: 1998-2003

35 Chrysant SG. Effectiveness and safety of phosphodiesterase 5 inhibitors in patients with cardiovascular disease and hypertension. Curr Hypertens Rep 2013; 15: 475-483

36 Chua R, Tar M, Melman A et al. Streptozotocin-induced diabetes results in time-dependent upregulation of the endothelin/rho-kinase pathway in rat corpus cavernosum smooth muscle. J Sex Med 2006; 3 (Suppl 1): 25

37 Chung E, Van CT, Wilson I et al. Penile prosthesis implantation for the treatment for male erectile dysfunction: clinical outcomes and lessons learnt after 955 procedures. World J Urol 2013; 31: 591-595

38 Clozel M, Gray GA, Breu V et al. The endothelin ETB receptor mediates both vasodilation and vasoconstriction in vivo. Biochem Biophys Res Commun 1992; 186: 867-873

39 Coombs PG, Heck M, Guhring $P$ et al. A review of outcomes of an intracavernosal injection therapy programme. BJU Int 2012; 110: 1787-1791

40 Corona G, Giorda CB, Cucinotta D et al. Gruppo di studio SUBITODE. Sexual dysfunction at the onset of type 2 diabetes: The interplay of depression, hormonal and cardiovascular factors. J Sex Med 2014; 11: 2065-2073

41 Corona G, Mannucci E, Petrone L et al. NCEP-ATPIII-defined metabolic syndrome, type 2 diabetes mellitus, and prevalence of hypogonadism in male patients with sexual dysfunction. J Sex Med 2007; 4: 10381045

42 Corrales JJ, Burgo RM, Garca-Berrocal B et al. Partial androgen deficiency in aging type 2 diabetic men and its relationship to glycemic control. Metabolism 2004; 53: 666-672

43 Dean J, Hackett GI, Gentile V et al. Psychosocial outcomes and drug attributes affecting treatment choice in men receiving sildenafil citrate and tadalafil for the treatment of erectile dysfunction: results of a multicenter, randomized, open-label, crossover study. J Sex Med 2006; 3: 650-661

44 Deyoung L, Chung E, Kovac JR et al. Daily use of sildenafil improves endothelial function in men with type 2 diabetes. J Androl 2012; 33: 176-180

45 Diemont W, Meuleman E. Neurological testing in erectile dysfunction. J Androl 1997; 18: 345-350

46 Dimmeler S, Zeiher AM. Endothelial cell apoptosis in angiogenesis and vessel regression. Circulation Research 2000; 87: 434-439

47 Drivsholm $T$, de Fine Olivarius $N$, Nielsen $A B$ et al. Symptoms, signs and complications in newly diagnosed type 2 diabetic patients, and their relationship to glycaemia, blood pressure and weight. Diabetologia 2005; 48: 210-214

48 Dyck PJ, Kratz KM, Karnes JL et al. The prevalence by staged severity of various types of diabetic neuropathy, retinopathy, and nephropathy in a population-based cohort: the Rochester Diabetic Neuropathy Study. Neurology 1993; 43: 817-824

49 Eardley I, Fisher W, Rosen RC et al. The multinational Men's Attitudes to Life Events and Sexuality study: the influence of diabetes on selfreported erectile function, attitudes and treatment-seeking patterns in men with erectile dysfunction. Int J Clin Pract 2007; 61: 14461453

50 Eardley I, Rosen R, Fisher WA et al. Attitudes toward treatment of erectile dysfunction: results from the MALES study. Eur Urol Suppl 2003; 2: 97 Abstract 377
51 Eid JF, Wilson SK, Cleves $M$ et al. Coated implants and "no touch" surgical technique decreases risk of infection in inflatable penile prosthesis implantation to $0.46 \%$. Urology 2012; 79: 1310-1315

52 El-Sakka AI, Tayeb KA. Peyronie's disease in diabetic patients being screened for erectile dysfunction. J Urol 2005; 174: 1026-1030

53 Fakjian N, Hunter S, Cole GW et al. An argument for circumcision. Prevention of balanitis in the adult. Arch Dermatol 1990; 126: 10461047

54 Fedele D, Coscelli C, Santeusanio F et al. Erectile dysfunction in diabetic subjects in Italy. Gruppo Italiano Studio Deficit Erettile nei Diabetici. Diabetes Care 1998; 21: 1973-1977

55 Feldman HA, Goldstein I, Hatzichristou DG et al. Impotence and its medical and psychosocial correlates: results of the Massachusetts Male Aging Study. J Urol 1994; 151: 54-61

56 Frøkjær JB, Brock C, Søfteland E et al. Macrostructural Brain Changes in Patients with Longstanding Type 1 Diabetes Mellitus - a Cortical Thickness Analysis Study. Exp Clin Endocrinol Diabetes 2013; 121: 354-360

57 Fonseca V, Seftel A, Denne J et al. Impact of diabetes mellitus on the severity of erectile dysfunction and response to treatment: analysis of data from tadalafil clinical trials. Diabetologia 2004; 47: 19141923

58 Gareri P, Castagna A, Francomano D et al. Erectile dysfunction in the elderly: an old widespread issue with novel treatment perspectives. Int J Endocrinol 2014; 17: Article ID 87867015 pages

59 Giagulli VA, Moghetti P, Kaufman JM et al. Managing erectile dysfunction in heart failure. Endocr Metab Immune Disord Drug Targets 2013; 13: 125-134

60 Giugliano F, Maiorino MI, Bellastella G et al. Adherence to Mediterranean diet and erectile dysfunction in men with type 2 Diabetes. J Sex Med 2010; 7: 1911-1917

61 Gluckman E. Hemochromatosis in heterozygotes. N Engl J Med 1996; 24: $1837-1838$

62 Goldstein I, Young JM, Fischer J et al. Vardenafil Diabetes Study Group. Vardenafil, a new phosphodiesterase type 5 inhibitor, in the treatment of erectile dysfunction in men with diabetes: a multicenter double-blind placebo-controlled fixed-dose study. Diabetes Care 2003; 26: 777-783

63 Goldstein I, Jones LA, Belkoff LH et al. Avanafil for the treatment of erectile dysfunction: a multicenter, randomized, double-blind study in men with diabetes mellitus. Mayo Clin Proc 2012; 87: 843-852

64 Grover-Páez F, Villegas Rivera G, Guillén Ortíz R. Sildenafil citrate diminishes microalbuminuria and the percentage of $\mathrm{A} 1 \mathrm{c}$ in male patients with type 2 diabetes. Diabetes Res Clin Pract 2007; 78: 136-140

65 Hakim LS, Goldstein I. Diabetic sexual dysfunction. Endocrinol Metab Clin North Am 1996; 25: 379-400

66 Hatzichristou D, Montorsi F, Buvat J et al. European Vardenafil Study Group. The efficacy and safety of flexible-dose vardenafil (levitra) in a broad population of European men. Eur Urol 2004; 45: 634-641

67 Hatzimouratidis K, Hatzichristou DG. A comparative review of the options for treatment of erectile dysfunction: which treatment for which patient? Drugs 2005; 65: 1621-1650

68 Hecht MJ, Neundorfer B, Kiesewetter F et al. Neuropathy is a major contributing factor to diabetic erectile dysfunction. Neurol Res 2001; 23: 651-654

69 Hellstrom WJ, Gittelman M, Karlin G et al. Vardenafil for treatment of men with erectile dysfunction: efficacy and safety in a randomized doubleblind, placebo-controlled trial. J Androl 2002; 23: 763-771

70 Hidalgo-Tamola J, Chitaley K. Type 2 diabetes mellitus and erectile dysfunction. J Sex Med 2009; 6: 916-926

71 Hidmark A, Fleming T, Vittas S et al. A New Paradigm to Understand and Treat Diabetic Neuropathy. Exp Clin Endocrinol Diabetes 2014; 122: 201-207

72 Incrocci L, Slob AK, Hop WC. Tadalafi 1 (Cialis) and erectile dysfunction after radiotherapy for prostate cancer: an open-label extension of a blinded trial. Urology 2007; 70: 1190-1193

73 International Diabetes Federation, IDF Diabetes atlas. $6^{\text {th }}$ edition 2013

74 Jarow JP. Risk factors for penile prosthetic infection. J Urol 1996; 156 (2 Pt 1): 402-404

75 Jesmin S, Sakuma I, Salah-Eldin A et al. Diminished penile expression of vascular endothelial growth factor and its receptors at the insulinresistant stage of a type II diabetic rat model: a possible cause for erectile dysfunction in diabetes. J Mol Endocrinol 2003; 31: 401-418

76 Jevtich MJ, Khawand NY, Vidic B. Clinical significance of ultrastructural findings in the corpora cavernosa of normal and impotent men. J Urol 1990; 143: 289-293 
77 Johannes $C B$, Araujo AB, Feldman HA et al. Incidence of erectile dysfunction in men 40 to 69 years old: longitudinal results from the Massachusetts Male Aging Study. J Urol 2000; 163: 460

78 Kadioglu A, Oktar T, Kandirali E et al. Incidentally diagnosed Peyronie's disease in men presenting with erectile dysfunction. Int J Impot Res 2004; 16: 540-543

79 Kamenov Z, Christov V, Yankova T. Erectile dysfunction in diabetic men - linked more to microangiopathic complications and neuropathy than to macroangiopathic disturbances. Journal of Men's Health and Gender 2007; 4: 64-73

80 Kamenov Z, Higashino H, Todorova $M$ et al. Physiological characteristics of diabetic neuropathy in sucrose-fed Otsuka Long-Evans Tokushima fatty rats. Methods Find Exp Clin Pharmacol 2006; 28: 13-18

81 Kamenov $Z$. Comparison of the first intake of vardenafil and tadalafil in patients with diabetic neuropathy and diabetic erectile dysfunction. JSM 2011; 8: 851-864

82 Kamenov Z. Erectile dysfunction in diabetic men. In: Sexual dysfunctions. Risk factors, psychological impact, and treatment (ed.). Frederique Courtois. Nova Science Publishers, Inc., New York: 2013 ISBN: 978-1-62808-768-0

83 Kamenov ZA, Parapunova RA, Georgieva RT. Earlier development of diabetic neuropathy in men than in women with type 2 diabetes mellitus. Gend Med 2010; 7: 600-615

84 Kamenov ZA, Petrova JJ, Christov VG. Diagnosis of diabetic neuropathy using simple somatic and a new autonomic (neuropad) tests in the clinical practice. Exp Clin Endocrinol Diabetes 2010; 118: 226-233

85 Kamenov ZA, Traykov LD. Diabetic autonomic neuropathy. Adv Exp Med Biol 2012; 771: 176-193

86 Kamenov ZA, Traykov LD. Diabetic somatic neuropathy. Adv Exp Med Biol 2012; 771: 155-175

87 Kang SG, Kim JJ. Udenafil: efficacy and tolerability in the management of erectile dysfunction. Ther Adv Urol 2013; 5: 101-110

88 Kawano K, Hirashima T, Mori S et al. Spontaneous long-term hyperglycemic rat with diabetic complications. Otsuka Long-Evans Tokushima Fatty (OLETF) strain. Diabetes 1992; 41: 1422-1428

89 Khan MA, Thompson CS, Jeremy JY et al. The effect of superoxide dismutase on nitric oxide-mediated and electrical field-stimulated diabetic rabbit cavernosal smooth muscle relaxation. BJU Int 2001; 87: 98-103

90 Klein R, Klein BE, Moss SE. Ten-year incidence of self-reported erectile dysfunction in people with long-term type 1 diabetes. J Diabetes Compl 2005; 19: 35

91 Levine LA, Dimitriou RJ. Vacuum constriction and external erection devices in erectile dysfunction. Urol Clin North Am 2001; 28: 335341

92 Lewis RW. Epidemiology of erectile dysfunction. Urol Clin North Am 2001; 28: 209-216

$93 \mathrm{Lin} \mathrm{C-S,} \mathrm{Ho} \mathrm{H-C,} \mathrm{Chen} \mathrm{K-C} \mathrm{et} \mathrm{al.} \mathrm{Intracavernosal} \mathrm{injection} \mathrm{of} \mathrm{vascular}$ endothelial growth factor induces nitric oxide synthase isoforms. BJU International 2002; 89: 955-960

94 Lu C-C, Jiann B-P, Sun C-C et al. Association of glycemic control with risk of erectile dysfunction in men with type 2 diabetes. J Sex Med 2009; 6: 1719-1728

$95 \mathrm{Lu} Y$, Shen $\mathrm{ZJ}$, Wang $\mathrm{H}$ et al. Ultrastructural changes of penile tunica albuginea in diabetic rats. Asian J Androl 2004; 6: 365-368

96 Malavige $L S$, Levy JC. Erectile dysfunction in diabetes mellitus. J Sex Med 2009; 6: 1232-1247

97 Malavige LS, Jayaratne SD, Kathriarachchi ST et al. Erectile dysfunction among men with diabetes is strongly associated with premature ejaculation and reduced libido. J Sex Med 2008; 5: 2125-2134

98 Manes C, Papanas N, Exiara $T$ et al. The Indicator Test Neuropad in the Assessment of Small and Overall Nerve Fibre Dysfunction in Patients with Type 2 Diabetes: a Large Multicentre Study. Exp Clin Endocrinol Diabetes 2014; 122: 195-199

99 Martin-Morales A, Sanchez-Cruz IJ, Saenz de Tejada I et al. Prevalence and independent risk factors for erectile dysfunction in Spain: results of the Epidemiologia de la Disfuncion Erectil Masculina Study. J Urol 2001; 166: 569-574

100 McMahon C. Efficacy and safety of daily tadalafil in men with erectile dysfunction previously unresponsive to on-demand tadalafil. J Sex Med 2004; 1: 292-300

101 Meuleman EJ, Eardley I, Rosen R et al. Attitudes toward treatment of erectile dysfunction: results from the MALES (Men's Attitudes toward Life Events and Sexuality) study. Presented at: Annual Meeting of the Asian Pacific Society of Sexual and Impotence Research; Cebu, Philippines; 2003
102 Ming XF, Viswambharan H, Barandier C et al. Rho GTPase/Rho kinase negatively regulates endothelial nitric oxide synthase phosphorylation through the inhibition of protein kinase B/Akt in human endothelial cells. Mol Cell Biol 2002; 22: 8467-8477

103 Montague DK, Angermeier KW, Lakin MM. Penile prosthesis infections. Int J Impot Res 2001; 13: 326-328

104 Montorsi F, Hellstrom WJ, Valiquette L et al. North American and European Vardenafil Groups. Vardenafil provides reliable efficacy over time in men with erectile dysfunction. Urology 2004; 64: 1187-1195

105 Montorsi P, Montorsi F, Schulman CC. Is erectile dysfunction the "tip of the iceberg" of a systemic vascular disorder? Eur Urol 2003; 44: 352-354

106 Moon du G, Yang DY, Lee CH et al. A therapeutic confirmatory study to assess the safety and efficacy of Zydena (udenafil) for the treatment of erectile dysfunction in male patients with diabetes mellitus. J Sex Med 2011; 8: 2048-2061

107 Moore CR, Wang R. Pathophysiology and treatment of diabetic erectile dysfunction. Asian J Androl 2006; 8: 675-684

108 Mulligan T, Frick MF, Zuraw QC et al. Prevalence of hypogonadism in males aged at least 45 years: the HIM study. Int J Clin Pract 2006; 60: 762-769

109 Musicki B, Palese MA, Crone JK et al. Phosphorylated endothelial nitric oxide synthase mediates vascular endothelial growth factor-induced penile erection. Biol Reprod 2004; 70: 282-289

110 National Intelligence Council. Global trends 2025: A Transformed World 2008

$111 \mathrm{Ng} \mathrm{KK}, \mathrm{Lim} \mathrm{HC}, \mathrm{Ng}$ FC et al. The use of sildenafil in patients with erectile dysfunction in relation to diabetes mellitus - a study of 1,511 patients. Singapore Med J 2002; 43: 387-390

112 Nieschlag E, Swerdloff R, Behre HM et al. Investigation, treatment, and monitoring of late-onset hypogonadism in males: ISA, ISSAM, and EAU recommendations. J Androl 2006; 27: 135-137

113 Nofzinger EA. Sexual Dysfunction in Patients with Diabetes Mellitus: The Role of a "Central" Neuropathy. Semin Clin Neuropsychiatry 1997; 2: 31-39

114 Padma-Nathan H. Efficacy and tolerability of tadalafil, a novel phosphodiesterase 5 inhibitor, in treatment of erectile dysfunction. Am J Cardiol 2003; 92: 19M-25M

115 Papapetropoulos A, García-Cardeña G, Madri JA et al. Nitric oxide production contributes to the angiogenic properties of vascular endothelial growth factor in human endothelial cells. Journal of Clinical Investigation 1997; 100: 3131-3139

116 Park HJ, Choi HK, Ahn TY et al. Efficacy and safety of oral mirodenafil in the treatment of erectile dysfunction in diabetic men in Korea: a multicenter, randomized, double-blind, placebo-controlled clinical trial. J Sex Med 2010; 7: 2842-2850

117 Park JK, Lee SO, Kim YG et al. Role of rho-kinase activity in angiotensin II-induced contraction of rabbit clitoral cavernosum smooth muscle. Int J Impot Res 2002; 14: 472-477

118 Park SH, Park SW, Cha BY et al. Comparison of the efficacy and safety of once-daily dosing and on-demand use of udenafil for type 2 diabetic patients with erectile dysfunction. Asian J Androl 2014

119 Penson DF, Latini DM, Lubeck DP et al. Do impotent men with diabetes have more severe erectile dysfunction and worse quality of life than the general population of impotent patients? Results from the Exploratory Comprehensive Evaluation of Erectile Dysfunction (ExCEED) database. Diabetes Care 2003; 26: 1093-1099

120 Phé V, Rouprêt $M$. Erectile dysfunction and diabetes: a review of the current evidence-based medicine and a synthesis of the main available therapies. Diabetes Metab 2012; 38: 1-13

121 Porst $H$, Oelke $M$, Goldfischer ER et al. Efficacy and safety of tadalafil $5 \mathrm{mg}$ once daily for lower urinary tract symptoms suggestive of benign prostatic hyperplasia: subgroup analyses of pooled data from 4 multinational, randomized, placebo-controlled clinical studies. Urology 2013; 82: 667-673

122 Porst H, Rajfer J, Casabŭ A et al. Long-term safety and efficacy of tadalafil $5 \mathrm{mg}$ dosed once daily in men with erectile dysfunction. J Sex Med 2008; 5: 2160-2169

123 Porst $H$, Rosen R, Padma-Nathan $H$ et al. The efficacy and tolerability of vardenafil, a new, oral, selective phosphodiesterase type 5 inhibitor, in patients with erectile dysfunction: the first at-home clinical trial. Int J Impot Res 2001; 13: 192-199

124 Porst HJB (ed.). Standard practice in sexual medicine. $1^{\text {st }}$ edition. Oxford: Blackwell, 2007

125 Potempa AJ, Ulbrich E, Bernard I et al. Vardenafil Study Group. Efficacy of vardenafil in men with erectile dysfunction: a flexible-dose community practice study. Eur Urol 2004; 46: 73-79 
126 Price $D$, Hackett $G$. Management of erectile dysfunction in diabetes: an update for 2008. Curr Diab Rep 2008; 8: 437-443

127 Price DE, Cooksey G, Jehu $D$ et al. The management of impotence in diabetic men by vacuum tumescence therapy. Diabet Med 1991; 8: 964-967

128 Redrow GP, Thompson CM, Wang $R$. Treatment strategies for diabetic patients suffering from erectile dysfunction: an update. Expert Opin Pharmacother 2014; 15: 1827-1836

129 Rees RW, Ziessen T, Ralph DJ et al. Human and rabbit cavernosal smooth muscle cells express Rho-kinase. Int J Impot Res 2002; 14: $1-7$

130 Reinhardt W, Darwiche K, Wiemann J et al. Sleep apnoe syndrome is associated with low serum testosterone levels and reversible by cpap- treatment. Exp Clin Endocrinol Diabetes 2004 112-P12

131 Rendell MS, Rajfer J, Wicker PA et al. Sildenafil for treatment of erectile dysfunction in men with diabetes: a randomized controlled trial. Sildenafil Diabetes Study Group. JAMA 1999; 281: 421-426

132 Rhoden EL, Teloken C, Ting HY et al. Prevalence of Peyronie's disease in men over 50-year-old from Southern Brazil. Int J Impot Res 2001; 13: 291-293

133 Rosen RC, Riley A, Wagner $G$ et al. The international index of erectile function (IIEF): a multidimensional scale for assessment of erectile function. Urology 1997; 49: 822-830

134 Ryan JG. Cost and policy implications from the increasing prevalence of obesity and diabetes mellitus. Gender Medicine 2009; 6: 86-108

135 Ryu JK, Cho KS, Kim SJ et al. Korean Society for Sexual Medicine and Andrology (KSSMA) Guideline on Erectile Dysfunction. World J Mens Health 2013; 31: 83-102

136 Saenz de Tejada I, Anglin G, Knight JR et al. Effects of tadalafil on erectile dysfunction in men with diabetes. Diabetes Care 2002; 25: 2159-2164

137 Saenz de Tejada I, Emmick J, Anglin G et al. The effect of IC351 taken as needed for treatment of erectile dysfunction in men with diabetes. Eur Urol 2001; 39: 16 abs.55

138 Safarinejad MR. Oral sildenafil in the treatment of erectile dysfunction in diabetic men: a randomized double-blind and placebo-controlled study. J Diabetes Complications 2004; 18: 205-210

139 Schulman CC, Shen W, Stothard DR et al. Integrated analysis examining first-dose success, success by dose, and maintenance of success among men taking tadalafil for erectile dysfunction. Urology 2004; 64: 783-788

140 Schwarzer $U$, Sommer F, Klotz $T$ et al. The prevalence of Peyronie's disease: Results of a large survey. BJU Int 2001; 88: 727-730

141 Seftel $A D$, Vaziri ND, Ni $Z$ et al. Advanced glycation end products in human penis: elevation in diabetic tissue, site of deposition, and possible effect through iNOS or eNOS. Urology 1997; 50: 1016-1026

142 Segal RL, Camper SB, Ma L et al. Prediction model for penile prosthesis implantation for erectile dysfunction management. Curr Med Res Opin 2014; 1: 1-7

143 Selvarajah D, Wilkinson ID, Maxwell M et al. Magnetic resonance neuroimaging study of brain structural differences in diabetic peripheral neuropathy. Diabetes Care 2014; 37: 1681-1688

144 Sheehy AM, Phung YT, Riemer RK et al. Growth factor induction of nitric oxide synthase in rat pheochromocytoma cells. Molecular Brain Research 1997; 52: 71-77

145 Siddiqui MA, Ahmed Z, Khan AA. Psychological Impact on Sexual Health among Diabetic Patients: A Review. International Journal of Diabetes Research 2012; 1: 28-31

146 Sidi AA, Becher EF, Zhang G et al. Patient acceptance of and satisfaction with an external negative pressure device for impotence. J Urol 1990; 144: 1154-1156

147 Siemons LJ, Mahler $\mathrm{CH}$. Hypogonadotrophic hypogonadism in hemochromatosis: recovery of reproductive function after iron depletion. J Clin Endocrinol Metab 1987; 65: 585-587

148 Sima AAF, Ristic H, Merry A et al. The primary preventional and secondary interventative effects of acetyl-L-carnitine on diabetic neuropathy in the BB/W-rat. J Clin Invest 1996; 97: 1900-1907

149 Singh $R$, Barden A, Mori T et al. Advanced glycation end-products: a review. Diabetologia 2001; 44: 129-146

150 Smith $A D$. Causes and classification of impotence. Urol Clin North Am 1981; 8: 79-89

151 Song WD, Yuan YM, Cui WS et al. Penile prosthesis implantation in Chinese patients with severe erectile dysfunction: 10-year experience. Asian J Androl 2013; 15: 658-661

152 Stoian DI, Craciunescu M, Anastasiu DD et al. Sustained life style changes - impact on sexual quality, metabolic parameters and QoL in overweight men with metabolic syndrome. Exp Clin Endocrinol Diabetes 2014 122-P172
153 Stracke H, Gaus W, Achenbach $U$ et al. Benfotiamine in diabetic polyneuropathy (BENDIP): results of a randomised, double blind, placebo-controlled clinical study. Exp Clin Endocrinol Diabetes 2008; 116: 600-605

154 Stuckey BG, Jadzinsky MN, Murphy LJ et al. Sildenafil citrate for treatment of erectile dysfunction in men with type 1 diabetes: results of a randomized controlled trial. Diabetes Care 2003; 26: 279-284

155 Sun L, Peng FL, Yu ZL et al. Combined sildenafil with vacuum erection device therapy in the management of diabetic men with erectile dysfunction after failure of first-line sildenafil monotherapy. Int J Urol 2014

156 Teerlink JR, Breu V, Sprecher $U$ et al. Potent vasoconstriction mediated by endothelin ETB receptors in canine coronary arteries. Circ Res 1994; 74: 105-114

157 Tefekli A, Kandirali E, Erol B et al. Peyronie's disease: A silent consequence of diabetes mellitus. Asian J Androl 2006; 8: 75-79

158 Tesfaye S, Stevens LK, Stephenson JM et al. Prevalence of diabetic peripheral neuropathy and its relation to glycaemic control and potential risk factors: the EURODIAB IDDM Complications Study. Diabetologia 1996; 39: 1377-1384

159 Traish A, Kim N. The physiological role of androgens in penile erection: regulation of corpus cavernosum structure and function. J Sex Med 2005; 2: 759-770

160 Tsertsvadze A, Fink HA, Yazdi F et al. Oral phosphodiesterase-5 inhibitors and hormonal treatments for erectile dysfunction: a systematic review and meta-analysis. Ann Intern Med 2009; 151: 650-661

161 Usta MF, Bivalacqua TJ, Yang DY et al. The protective effect of aminoguanidine on erectile function in streptozotocin diabetic rats. J Urol 2003; 170: 1437-1442

162 Valiquette L, Young JM, Moncada I et al. Sustained efficacy and safety of vardenafil for treatment of erectile dysfunction: a randomized double-blind, placebo-controlled study. Mayo Clin Proc 2005; 80: 1291-1297

163 Vardi M, Nini A. Phosphodiesterase inhibitors for erectile dysfunction in patients with diabetes mellitus. Cochrane Database Syst Rev 2007; 24: CD002187

164 Vardi Y, Sprecher E, Gruenwald I. Logistic regression and survival analysis of 450 impotent patients treated with injection therapy: long-term dropout parameters. J Urol 2000; 163: 467-470

165 Vickers MA, Wright EA. Erectile dysfunction in the patient with diabetes mellitus. Am J Manag Care 2004; 10 (1 Suppl): S3-S11

166 Vinik A, Richardson D. Erectile dysfunction in diabetes. Diabetes Rev 1998; 6: 16-33

167 Vinik AI, Holland MT, Le Beau JM et al. Diabetic neuropathies. Diabetes Care 1992; 15: 1926-1975

168 Wallis RM, Corbin JD, Francis SH et al. Tissue distribution of phosphodiesterase families and the effects of sildenafil on tissue cyclic nucleotides, platelet function, and the contractile responses of trabeculae carneae and aortic rings in vitro. Am J Cardiol 1999; 83: 3C-12C

169 Walsh TJ, Hotaling JM, Smith A et al. Men with diabetes may require more aggressive treatment for erectile dysfunction. Int J Impot Res 2014; 26: 112-115

170 Wang C, Nieschlag E, Swerdloff R et al. International Society of Andrology (ISA); International Society for the Study of Aging Male (ISSAM); European Association of Urology (EAU); European Academy of Andrology (EAA); American Society of Andrology (ASA). Investigation, treatment, and monitoring of late-onset hypogonadism in males: ISA ISSAM, EAU, EAA, and ASA recommendations. J Androl 2009; 30: 1-9

171 Wang $H$, Eto $M$, Steers WD et al. RhoA-mediated Ca2 + sensitization in erectile function. J Biol Chem 2002; 277: 30614-30621

172 Wilkinson ID, Selvarajah D, Greig $M$ et al. Magnetic resonance imaging of the central nervous system in diabetic neuropathy. Curr Diab Rep 2013; 13: 509-516

173 Wilson SK, Carson CC, Cleves MA et al. Quantifying risk of penile prosthesis infection with elevated glycosylated haemoglobin. J Urol 1998; 159: 1537-1539 [discussion 1539-1540]

174 Wilson SK, Delk JR $2^{\text {nd }}$. Inflatable penile implant infection: predisposing factors and treatment suggestions. J Urol 1995; 153 (3 Pt 1): 659-661

175 Wing RR, Rosen RC, Fava JL et al. Effects of weight loss intervention on erectile function in older men with type 2 diabetes in the look AHEAD trial. J Sex Med 2010; 7: 156-165

176 Yagihashi S, Yamagishi S, Wada R. Pathology and pathogenetic mechanisms of diabetic neuropathy: Correlation with clinical signs and symptoms. Diabetes Res Clin Pract 2007; 77 (1 suppl): S184-S189

177 Yan SF, Ramasamy R, Schmidt AM. Mechanisms of disease: advanced glycation end-products and their receptor in inflammation and diabetes complications. Nat Clin Pract Endocrinol Metab 2008; 4: 285-293 
178 Yilmaz D, Bayatli N, Un O et al. The effect of intracavernosal avanafil, a newer phosphodiesterase- 5 inhibitor, on neonatal type 2 diabetic rats with erectile dysfunction. Urology 2014; 83: 508

179 Young MJ, Boulton AJM, McLeod AF et al. A multicentre study of the prevalence of diabetic peripheral neuropathy in the UK hospital clinic population. Diabetologia 1993; 36: 150-156
180 Zargaroff S, Sharma $V$, Berhanu $D$ et al. National trends in the treatment of penile prosthesis infections by explantation alone vs. immediate salvage and reimplantation. J Sex Med 2014; 11: 1078-1085

181 Ziegler D. Treatment of diabetic polyneuropathy: Update 2006. Ann N Y Acad Sci 2006; 1084: 250-266 